\title{
Article
}

\section{A systematic investigation into the flowback cleanup of hydraulic-fractured wells in unconventional gas plays}

Nasriani, Hamid Reza, Jamiolahmady, Mahmoud, Saif, Tarik and Sánchez, Jose

Available at http://clok.uclan.ac.uk/22558/

Nasriani, Hamid Reza ORCID: 0000-0001-9556-7218, Jamiolahmady, Mahmoud, Saif, Tarik and Sánchez, Jose (2018) A systematic investigation into the flowback cleanup of hydraulic-fractured wells in unconventional gas plays. International Journal of Coal Geology, 193 . pp. 46-60. ISSN 0166-5162

It is advisable to refer to the publisher's version if you intend to cite from the work. http://dx.doi.org/10.1016/j.coal.2018.04.012

For more information about UCLan's research in this area go to http://www.uclan.ac.uk/researchgroups/ and search for <name of research Group>.

For information about Research generally at UCLan please go to http://www.uclan.ac.uk/research/

All outputs in CLoK are protected by Intellectual Property Rights law, including Copyright law. Copyright, IPR and Moral Rights for the works on this site are retained by the individual authors and/or other copyright owners. Terms and conditions for use of this material are defined in the policies page. 


\title{
A Systematic Investigation into the flowback cleanup of hydraulic-fractured wells in unconventional gas plays
}

\author{
Hamid Reza Nasriani ${ }^{1}$, Mahmoud Jamiolahmady ${ }^{1}$, Tarik Saif ${ }^{1}$ \& Jose Sánchez ${ }^{1}$ \\ ${ }^{1}$ Heriot-Watt University, Institute of Petroleum Engineering, Edinburgh, United Kingdom
}

\begin{abstract}
This paper conducts an extensive investigation into fracture cleanup efficiency by considering several pertinent parameters instantaneously over a wide practical range. Injection, shut-in and production stages of the fracturing operation were simulated for 32 sets consisting of 113072 runs. To perform such a large number of simulation runs, a computer code was utilised to routinely read input data, implement the simulation runs and produce output data. In each set (which consists of 4096 runs), instantaneous impacts of twelve different parameters (i.e., fracture and matrix permeability, Brooks matrix capillary pressure (Pc) parameters, and Brooks-Corey relative permeability parameters) were investigated. To sample the domain of variables, full factorial experimental design (two-level FFS) was employed. The linear surface methodology was used to map the simulation output, which is the loss in gas production (GPL), compared to the clean case (i.e., 100\% clean-up) after three production periods of 10,30 and 365 days.

The impact of various combinations of fracture fluid injection volume, fracture length, shut-in soaking time, matrix permeability variation range and drawdown on GPL were studied in different sets. Additionally, more simulation sets were performed to capture the impact of hysteresis, layering and mobile formation water on the clean-up efficiency.

Results indicated that in line with some literature data, factors that controlled the mobility of FF inside the fracture had the most significant impact on cleanup efficiency. It was also noted that injecting high volumes of FF, into very tight formations significantly delayed clean-up and impaired gas production. The effect of varying other parameters such as extending soaking
\end{abstract}


time or increasing pressure down in such a case delivered negligible GPL improvement. Introducing hysteresis made clean-up slightly faster in all production periods.

The impact of the gravity segregation was discussed in this study. Considering the layered systems, it was indicated that in the top layer, the fracture mobility coefficients were more important than the ones in the bottom layer whist capillary pressure seems to become more important in deeper layers compared to the top layers.

Additionally, a slower clean-up was observed for sets with larger initial water saturation compared to those cases with immobile water saturation due to the detrimental effect of mobile water on gas production. In some cases, with significantly high values of water saturation, using chemicals (which IFT reducing agents) to reduce Pc could reduce GPL and improve cleanup efficiency.

These findings contribute to the further understanding of the fracture fluid cleanup process and provide practical guidelines to achieve economically successful hydraulic fracturing operations, which are popular but expensive for tight and ultra-tight reservoirs.

Keywords: Post Fracturing Cleanup; unconventional fields; Hydraulic Fracturing; Flowback; productivity; fracturing fluid

\section{Introduction \& Literature Review}

Hydraulic fracturing (HF), also known as Hydro-fracking, is one of the most widely used stimulation techniques in the oil and gas industry to enhance the production from unconventional fields. A hydraulic fracture is initiated and propagated by injecting a fluid with high pressure into the formation. The injection fluid also referred to as fracturing fluid (FF), is typically water albeit with suspended solid materials, usually sand or another type of proppants added to keep the fracture open. After fracturing, oil, gas and FF flow towards the well much more easily because of the presence of the fractures.

Hydraulic fracturing is widely employed to increase the productivity of wells in tight and ultratight fields. However, this encouraging approach sometimes is not successful to meet the predicted production enhancement. The most common cause is an inefficient cleanup of the previously injected fracturing fluid.

Several studies have been conducted to understand this underperformance and to capture the impact of the pertinent parameters affecting the efficiency of FF cleanup 
Tannich (1975) reported that the production loss due to FF presence in the fracture and matrix is more significant at the early production periods. Tannich also indicated that as the fracture length increases it takes a longer time for the well to cleanup. Additionally, he showed that the lower the fracture conductivity, the slower the cleanup process. Cooke Jr. \& C.E., (1973) and Cooke Jr. \& Cooke, (1975) investigated the cleanup efficiency experimentally and concluded that the FF presence in the fracture could substantially reduce the fracture conductivity. Numerous numerical and parametric works were conducted on the FF cleanup and its failure to further study the HF operation. (Ahmed et al., 1979; Montgomery et al., 1990; Bennion et al., 2000; Mahadevan and Sharma, 2005; Jamiolahmady et al., 2009, 2014; Bazin et al., 2010; Gdanski and Walters, 2010; Ghahri, 2009, 2010; Ghahri et al., 2011; Nasriani et al., 2014a; Nasriani et al., 2014b; Nasriani and Jamiolahmady, 2018).

Cheng (2012) highlighted that the flow of the fracturing fluid and water within the created and natural fractures has a substantial influence on the efficiency of hydraulically fractured wells. He also reported that a number of mechanisms govern the flow of water within a fracture. He constructed a numerical model to study the water saturation distribution within the fracture over production time and demonstrate its detrimental impact on gas production. He concluded that capillary forces and gravity segregation could have a significant impact on gas production. Agrawal and Sharma (2015) constructed a three-dimensional planar hydraulic fracture numerical model to study the impact of different mechanisms within the fracture, i.e., capillary forces, viscous forces (relative permeability) and gravity forces. They concluded that liquid loading is very likely to occur in ultratight gas fields when the well is produced under the regular operational constraints. They recommended some guidelines to minimalize the impact of liquid loading on the gas production.

Ghanbari and Dehghanpour (2016) studied the governing parameters on FF and gas production during the clean-up period using numerical simulations. They noticed that the imbibition of FF deeper into the matrix during the shut-in time could increase the gas productivity at early production times. Therefore they highlighted that the early time flowback and gas production depends on capillary forces, the fracture networks' complexity and the shut-in time. They noted that having higher capillary forces could result in higher gas production rates only during the early production times but the complexity of the created fracture networks has a significant impact on flowback recovery and gas production rates.

$\mathrm{Xu}$ et al (2016) developed a mathematical model to simulate the early time FF flowback and gas production. They considered several drive mechanisms during the shut-in time including 
expansion of gas build-up, water expansion and fracture closure. They concluded that the gaswater ratio (GWR) plots for shale gas formations follow a V-shaped trend, the first region, i.e., decreasing GWR during early gas production stage indicates the two-phase production from the fracture. The second region, i.e., increasing GWR during late gas production indicates the water displacement by the gas that flows from the matrix into the fracture.

Zhou et al., (2016) selected a set of different wells (187 wells) of four different geological settings. From this set of wells, they considered different factors that affect FF flowbackproduction including the number of hydraulic-fracture stages, lateral length, vertical depth, proppant mass applied, proppant size, fracture-fluid volume applied, treatment rate, and shutin time. They studied the correlation between flowback data and well completion for the four different geological groups. They estimated FF flowback volume in a spatial domain as a function of the aforementioned factors.

Wang and Leung (2016) conducted a quantitative investigation of the fluid and rock properties and geomechanics that control flowback recovery. They noticed that there is an important interaction between imbibition and geomechanics during FF and gas production. They highlighted that fracture cloture could increase the imbibition process and reduce the fracture conductivity due to a reduction in the pressure within the fracture.

Lai et al., (2017) conducted a numerical simulation to capture the impact of wettability, the viscosity of FF and FF filtration on water blockage and gas productivity in hydraulically fractured wells. They showed that FF is retained within the matrix at high surface tension values. They showed that a reduction in the interfacial tension could increase the flowback recovery and consequently improve the gas recovery. They also demonstrated that higher FF viscosity could significantly increase the damage and consequently impair the gas productivity. (Fu et al., 2017) constructed diagnostic plots to highlight the physics of flow in two different regions. Region 1 refers to the pressure reduction duration within the fractures, and Region 2 denotes the breakthrough of oil \& gas into the active fracture network. They indicated that the duration of Region 1 is governed by original field pressure and the type of hydrocarbon. They concluded that total injected FF volume, perforation intervals, and the number of clusters are the most important parameters to optimise the fracturing operation.

Although these works were significant steps to better understand the flowback cleanup in postfracturing operation, they did not consider the impact of all pertinent parameters instantaneously over a wide practical range on the post-fracturing cleanup. 
In the Gas Condensate Recovery (GCR) team at Heriot-Watt University, Ghahri et al.(2009) conducted a single parameter analysis on the cleanup efficiency of the fracture in tight formations. This line of study was then extended to investigate the impact of sixteen different but pertinent parameters simultaneously for two simulation sets (with different volume of injected FF) on the cleanup performance (Ghahri et al., 2010, 2011). They employed experimental design linked with the response surface model methodology to capture the impact of the pertinent parameters. They reported that the mobility of FF and gas have a significant impact on the gas production and cleanup efficiency. They also showed that the higher the volume of the injected FF, the higher the gas production loss and consequently, it takes a longer time for flowback to be removed from the matrix and the fracture.

The two numerical simulation works that were conducted by Ghahri et al., $(2009,2011)$ required a very long central processing unit time (CPU time). Therefore, it limited the authors to the analysis of two sets of simulations with sixteen pertinent parameters. To facilitate studying more simulation sets and therefore analysing different scenarios of cleanup in unconventional formations, Jamiolahmady et al. (2014) reduced the number of the related parameters from sixteen to twelve by eliminating four variables that had the smallest effect on cleanup efficiency. The twelve pertinent parameters were fracture and matrix permeability, lambda, surface tension and fluid (gas and FF) mobility pertinent parameters in the fracture and matrix. As a result, more simulation sets with shorter CPU time were conducted in that study and the follow-up work (Nasriani et al., 2014a \& b, Nasriani and Jamiolahmady, 2018). In these studies, the authors ran forty five different sets of simulations with different shut-in time periods, pressure drawdown during the following production stage, the total volume of injected FF and different matrix permeability ranges (Jamiolahmady et al., 2014; Nasriani and Jamiolahmady, 2018). They concluded that a decrease in matrix permeability variation range resulted in a higher gas production loss and delayed the cleanup process. They mentioned that if the matrix permeability is increased, a better the cleanup performance is achieved. They also showed that the impact of Pc is more distinct in low drawdown pressure and/or prolonged soaking time sets (Jamiolahmady et al., 2014; Nasriani and Jamiolahmady, 2018).

\subsection{The purpose of this study}

This current work extends the line of studies that were previously conducted by various members of The Gas Condensate Recovery (GCR) team at Heriot-Watt University (Ghahri et al., 2009, 2011a; Jamiolahmady et al., 2014; Alajmi 2012 (his thesis) Nasriani and 
Jamiolahmady, 2018). This work presents a more extensive investigation of the impact of parameters that affect cleanup of the hydraulic fracturing operation. This includes studying the impact of different combinations of varying fracture fluid injection volume, shut-in soaking time, matrix permeability variation range and drawdown on GPL in sets, which had not been considered in the previous studies. Additionally, more simulation runs have been performed to capture the impact of hysteresis, layering and mobile formation water on the cleanup efficiency. In this work, Altogether, 32 new sets (i.e., 131072 simulation runs) were performed to further improve the understanding of the hydraulic fracturing operation.

Similar to our previous work by same authors (Nasriani and Jamiolahmady, 2018) significant efforts were devoted to fitting the response surface models to the output data that could be more demonstrative of the trends noted in the implemented numerical simulations, that is, the dependent variable, i.e., gas production loss, was transferred to another domain. The dependency of the dependent variable, i.e., gas production loss, in the new domain, to the 12 pertinent parameters were investigated at different production stages (ten, thirty and 365 days), by the tornado charts of fitted response surface coefficients, frequency of simulation runs with obtained GPL and saturation distribution maps of FF in the matrix in the vicinity of fracture and within the fracture.

\section{Methodology}

Analysing a large number of numerical simulation runs is a real challenge and therefore, should be conducted in a very organised manner or it will lose its advantage. This section introduces the analysis method which was assumed in this study and defines terminologies that are used to make it more convenient for the reader to follow the presented results and conclusions. Figure 1 shows a flowchart explaining the workflow of the analysis of the postfracturing cleanup in this study. As it is demonstrated in the flowchart, the previously developed numerical model was modified and then validated. After the validation of the model, five different scenarios were considered. It should be noted that several sets were included in each scenario. In this approach, the full factorial experimental design sampling technique is employed to each set to generate the input to the simulation models, and at that point, the numerical simulation is carried out. Subsequently, an appropriate surface model is fitted to the results of each set. Finally, the results of different sets are analysed and compared.

\subsection{Development and Validation of a Numerical Model for this study}


In this study, A combination of several mechanisms have been considered to investigate the FF flowback in tight and ultratight dry gas formations extensively, i.e., imbibition, drainage, viscous forces, gravity segregation and hysteresis. In line with the team's other investigations (e.g., Nasriani and Jamiolahmady 2018), it was assumed that the FF fills in the fracture instantly during the injection period eliminating the need to consider the impact of parameters on this flow period. In this procedure, the FF saturation distribution within the matrix, which contributes to the performance of cleanup to a much greater extent, is obtained by the simulator but that within the fracture is assumed to happen instantly, which is somewhat consistent with what happens in reality and reported in the literature.

In order to investigate a fractured well, a pre-fractured single well model, which had been built using ECLIPSE 100 (Schlumberger, 2015), was used. For this study, a single porosity model was considered. The initial reservoir pressure and matrix porosity were 7500 psi and 15\% respectively. Table 1 displays the fracture and the reference model dimensions used in this study. The fracture half-length (Xf) was either $400 \mathrm{~m}$ (long fracture sets) or 100m (short fracture sets). The gas properties of the reference model are tabulated in Table 2. The fracturing fluid, FF, was considered as water. The viscosity of $0.5 \mathrm{cp}$ and compressibility of $5 \mathrm{e}-6$ (1/psi) were considered for FF. For the base set defined as a reference, FF volume of twice the volume of the fracture was considered for the injection stage. Since a section of the system (a quarter of the system) was modelled (Figure 2), FF with a total injection volume of either $64 \mathrm{~m}^{3}$ (long fracture sets) or $16 \mathrm{~m}^{3}$ (short fracture sets) was considered. That is, the FF volume per fracture length, defined as ( $=$ Vinj / Lf, $\mathrm{m}^{3} / \mathrm{m}$ ) was equal to $0.16 \mathrm{~m}^{3} / \mathrm{m}$ equivalent to $2 \mathrm{FVR}$ (The injected $\mathrm{FF}$ volume to fracture volume ratio) defined as $\mathrm{FVR}=\mathrm{Vinj} / \mathrm{Vf}, \mathrm{m}^{3} / \mathrm{m}^{3}$. In the second stages of the modelling, gas and FF phases were allowed to produce under controlled bottom-hole flowing pressure. After FF injection and before production, the well was shut-in for two days. It should be noted that local grid refinement (LGR) was applied to the areas near fracture face to more accurately capture the FF flowback.

To validate the model developed for fractured well cleanup operation, the predicted bottom hole pressures from the reservoir simulation outputs were compared with analytical models for the early time flow period. The governing equations for early time flow period have been discussed elsewhere (Nasriani and Jamiolahmady, 2018).

Figure 3 shows the predicted bottom hole pressure by the analytical model versus those of the simulation model with $\mathrm{R}^{2}$ of 0.9978 which is satisfactory. 


\subsection{Pertinent Parameters affecting the Efficiency of Fracturing Fluid Cleanup}

As it was mentioned earlier, 12 pertinent parameters have been considered in this work. The exponents of Brooks-Corey (gas or FF) relative permeability curve $\left(\mathrm{n}_{\mathrm{gi}}\right.$ and $\mathrm{n}_{\mathrm{wi}}$, where i refer to inside fracture or inside matrix), i.e., ngf, nwf, ngm \& nwm respectively.

The endpoints of Brooks-Corey (gas or FF) relative permeability curve $\left(\mathrm{K}_{\operatorname{maxgi}}\right.$ and $\mathrm{K}_{\operatorname{maxwi}}$, where $\mathrm{i}$ refer to inside fracture or inside matrix), i.e., $\mathrm{K}_{\operatorname{maxgf}}, \mathrm{K}_{\operatorname{maxwf}}, \mathrm{K}_{\operatorname{maxgm}} \& \mathrm{~K}_{\operatorname{maxwm}}$ respectively.

Three parameters control capillary pressure. These parameters are permeability of the matrix $\left(\mathrm{K}_{\mathrm{m}}\right)$, surface tension (IFT) and pore size distribution index $(\lambda)$.

Table 3 displays the ranges of variation of relevant parameters (12 parameters) that were considered in the numerical simulations during this study. These variables and their range were considered based on the understanding of the process gained by the work of the GCR team, i.e., Ghahri (2010) and Alajmi (2012), literature data and support of the GCR sponsors of the project that provided the real field data information. As shown in Table 3, the other remaining 6 parameters, i.e., porosity and critical gas and water saturations in the matrix and fracture and pressure drawdown (DP), were considered constant in each simulation set. Porosity was fixed at a value of 0.15 and both residual gas saturation in the matrix (Sgrm) and fracture (Sgrf) were fixed at a value of 0.1. Additionally, critical water saturation in the matrix ( $\mathrm{Swcm}$ ) and fracture (Swcf) were fixed at a value of 0.15 .

Equations 1, 2, $3 \& 4$ describe the capillary pressure (Thomas et al., 1968) and relative permeability curves (Brooks and Corey, 1966) for data of Table 3.

$$
\frac{P d}{I F T}=0.0075 \times K^{-0.5}
$$

- Entry pressure Pd, bar, (Thomas et al., 1968)

- Interfacial tension IFT (dyne/cm)

- Matrix permeability $(\mathrm{K}(\mathrm{mD}))$

$$
\begin{aligned}
& \left(\frac{P d}{P c}\right)^{\lambda}=\frac{S w-S w r}{1-S w r} \\
& k_{r w}=K_{\max w} \times\left(\frac{S w-S w r}{1-S w r-S g r}\right)^{n w}
\end{aligned}
$$


Equation 2 is used to calculate Pc. This equation is linked to Equation 1.

The impact of pressure drop (DP), which was considered constant, was treated separately, i.e. different sets of simulations were considered for each pressure drop (please note Table 4.a to 4.c). This brings the total number of variables from 16 in Ghahri's work (Ghahri, 2010) to 12 in Alajmi's work (Alajmi, 2012) and this work. Based on this number of parameters, each fracture well model (mentioned earlier) requires 4096 simulation runs (for a two-level full factorial sampling (FSS) design), this brings the total number of simulation runs for all the analysed 32 sets of 12-parameter models to 131,072 simulation runs. As it was mentioned previously Ghahri (2010) had conducted 4 sets and Alajmi (2012) had 7 sets and those runs did not investigate the cases that are addressed in this work. Furthermore, the results of each Set are compared either with base reference set or with similar sets reported in this work or Alajmi (2012) highlighting the impact of pertinent parameters studied in this work.

In this study, to analyse the results more efficiently using the response surface method, described below, the parameters are scaled between 0 and 1 with zero corresponding to the lower bound of variation of a parameter and 1 corresponding to the maximum point. It also should be highlighted that in FFS approach, as one parameter changes and kept the other constant and due to the nature of the sensitivity analysis, no correlation is considered between the parameters that might be dependent on one another (e.g., Permeability and porosity, or Swi and porosity)

\subsection{Main Response \& Application of Response Surface Method (RSM)}

The key output, i.e., main response, in this work is Gas Production Loss (GPL, \%). GPL is described as a measure of unclean fracture cumulative production (FGPT) deviation from the cumulative production of the case with a completely clean fracture (Ghahri et al., 2009, 2011b; Jamiolahmady et al., 2009).

$$
G P L=100 \times\left[\frac{F G P T_{\text {clean }}-F G P T_{\text {un - clean }}}{F G P T_{\text {clean }}}\right]
$$

In real field applications, it is hard, if not technically impractical, to get a completely clean fracture job. However, if one understands the relevant parameters and their impact on the cleanup procedure then it will be possible to define real field strategies to approach a $100 \%$ clean fracture job. One of the main benefits of using GPL is that GPL is a normalised quantity, 
it allows the user to compare different cases more easily and draw conclusions more appropriately. In this work, the impact of 12 parameters on GPL is addressed. In this exercise, a parameter is assumed to have a positive impact if it decreases the GPL, i.e., more gas production, while parameter's value is increased, whereas a negative impact parameter is the one, which increases GPL as parameter's value is increased.

Response Surface Method, i.e., RSM, is a valuable means of analysing and expressing the sensitivity of a set of variables relevant to a specific output. It is a combination of mathematical and statistical approaches to find a suitable relationship between the main response $\mathrm{y}$ and independent variables $\mathrm{x} 1, \mathrm{x} 2, \mathrm{x} 3 \ldots \mathrm{xn}$. The fitted polynomial function $(\mathrm{f}(\mathrm{xi}))$ is called the response surface model. This model can be a linear or quadratic (with or without interaction term) and described by Equation 6 (Joshi et al., 1998).

$$
y=a_{0}+\sum_{k=1}^{n} a_{k} x_{k}+\sum_{i=1}^{n} \sum_{j=1}^{n} a_{i} a_{j} x_{i} x_{j}+\sum_{l=1}^{n} a_{l} x_{l}^{2}
$$

In Equation 6, four different models could be considered:

- Linear Surface model, if constant $\left(\mathrm{a}_{0}\right)$ and linear terms $\left(\mathrm{a}_{\mathrm{k}} \mathrm{x}_{\mathrm{k}}\right)$ are considered.

- Interactive Linear Surface model, if the interaction terms $\left(\mathrm{a}_{\mathrm{i}} \mathrm{a}_{\mathrm{j}} \mathrm{x}_{\mathrm{i}} \mathrm{x}_{\mathrm{j}}\right)$ are also considered.

- Pure Quadratic Surface model, if constant \& linear and quadratic terms $\left(\mathrm{a}_{1}^{2} \mathrm{x}_{1}^{2}\right)$ are considered.

- Full Quadratic Surface model, if constant\& linear, interaction and quadratic terms are considered.

The interactive and non-interactive linear response models were employed to define the dependency of gas production loss (GPL) on pertinent parameters affecting the cleanup performance of an HFW. A MATLAB code (The MathWorks, 2013) was developed for sets to link different stages of the simulation and to model the two-level full factorial sampling approach.

It should be highlighted that considerable efforts were dedicated to fit equations that are more representative of the trends observed in the performed simulations. In this exercise, the main dependent variable's (i.e. GPL) domain of the fitted response surface model (RSM) was changed. That is, without the domain change there were cases whereby the predicted GPL was very different from the actual value and sometimes giving unrealistic negative or greater than $100 \%$, GPL values. However, with the domain change, this issue was eliminated. 
To overcome this difficulty and to obtain more accurate RSM and benefiting from the support of MATLAB mathematical package technical support team, the GPL variable has been transferred to a different domain. That is, instead of defining the model with the output as GPL, the regression model has been defined in such a way that gives Log of (GPL/(101-GPL)) as the output. This ensures that GPL varies within the desired interval $[0,100]$. A full discussion on the domain change is discussed elsewhere (Nasriani and Jamiolahmady, 2018; Nasriani et al., 2014; Nasriani et al., 2014a). It is noted that calculated GPL values using RSM in new domain correctly vary in the 0 to $100 \%$ range.

\subsection{Analysis Methodology}

In this study, as it is shown in Table 4a-c, the results of 32 different sets are investigated as follow:

- Long fracture well $(400 \mathrm{~m})$ base reference set (1 set)

- Two-layer long fracture sets (4 Sets), To study the impact of gravity on the cleanup.

- Long fracture sets with/without hysteresis (2 Sets), to capture the impact of hysteresis on clean-up analysis

- Long fracture sets $(400 \mathrm{~m})$ with high FF injection volume (15 sets)

- Short fracture sets $(100 \mathrm{~m})$ with high FF injection volume, (8 sets)

- Long fracture sets with initial mobile water saturation (2 sets).

The results have been compared with those of a base reference set and other similar sets. These sets have identical reservoir dimensions as those of the base reference set but differ in the shut-in time period (ST), matrix permeability variation range (Kmr), pressure drawdown (DP) and length of the hydraulic fracture.

For the simulation sets, there is a Base Reference set with parameters in the ranges indicated in Table 3 as defaulted values. The other sets are cited based on the differences of the parameters variation range from the Base Reference set, i.e., in each set any parameter that has a tick mark has the defaulted values otherwise the parameter's value is stated in the table. All sets that have been considered in this work are listed here for the reference and convenience. The analysed sets in this study are listed in Table $4 \mathrm{a}$ and Table $4 \mathrm{~b}$.

It should be noted that the results of each Set are compared either with base reference set or with similar Sets reported highlighting the impact of pertinent parameters studied in this work. This means that set numbering might not be monotonic for sets reported in different sections.

\section{Results \& Discussions}




\subsection{The Base Reference Set}

The base reference set was thoroughly discussed elsewhere (Nasriani and Jamiolahmady, 2018), therefore in this work, a brief summary of the main observations are presented here. From data of Figure 4, it is noted that fracture permeability $\left(\mathrm{K}_{\mathrm{f}}\right)$, with the highest absolute coefficient value of 1 , the most important parameter in fracture cleanup, i.e. the larger the $\mathrm{Kf}$, the lower the GPL. This observation is in line with having a high coefficient for the Corey exponent and endpoint for FF relative permeability curve $\left(\mathrm{n}_{\mathrm{wf}}\right.$ and $\left.\mathrm{K}_{\operatorname{maxwf}}\right)$. That is, they all show that cleanup efficiency is improved if fracture fluid mobility inside the fracture improves.

The impacts of surface tension (IFT), pore size distribution index $(\lambda)$ are affecting the results such that if capillary pressure increases, there is a reduction in GPL or an improvement in the cleanup, as a larger volume of FF is imbibed into the matrix, leaving fracture clean for gas to flow. However, it should be noted that $\mathrm{K}_{\mathrm{m}}$ also affects Pc, which is discussed below.

Matrix permeability $\left(\mathrm{K}_{\mathrm{m}}\right)$ has a coefficient of -0.4 , suggesting that the higher the $\mathrm{K}_{\mathrm{m}}$ the lower GPL. An increase in matrix permeability $\left(\mathrm{K}_{\mathrm{m}}\right)$ influences GPL in two ways:

(i) It allows better mobility for fluids in the matrix during injection and production periods.

(ii) It reduces capillary pressure.

According to what was mentioned above, a decrease in Pc should increase GPL. Hence, it could be concluded that in this base reference set, the contribution of $\mathrm{K}_{\mathrm{m}}$ in improving fluid mobility, particularly that of the FF flowing into the matrix, results in the better cleanup, i.e. lowering GPL.

These observations also suggest that in set 1 base reference set, using chemicals (IFT reducing agents) to reduce Pc could increase GPL and impairs cleanup efficiency.

From cumulative frequency data of histogram shown in Figure 7, it is noted that during the first 10 days of production, over $83 \%$ of simulation runs have GPL larger than $20 \%$, $\mathrm{GPL}_{20}=17 \%$. It is evident that GPL decreases significantly at longer production time. That is, the frequency of runs with GPL more than $20 \%$ is about $68 \%$ and $28 \%$ after 30 days and 1 year of production, correspondingly, i.e., the longer the production time the cleaner the fracture and consequently the lower the GPL.

The main observations of the base reference set are therefore (i). Enhancement in fracture conductivity and mobility of FF within the fracture results in an improved cleanup efficiency (ii) retaining high Pc by maintaining high IFT results in a cleaner fracture and higher cleanup efficiency. 
The cumulative gas and water flowback of the best and worst case scenarios are shown in Figure 8. The best-case scenario with the lowest GPL is the one for which all parameters (with a positive scaled coefficient value) are set to the minimum limit of their variation range while all other parameters (with a negative scaled coefficient value) are set to the maximum limit of their variation range. Contrariwise, the worst-case scenario with the highest GPL is the one for which all parameters (with a positive scaled coefficient value) are set to their maximum limit of range while all other parameters (with a negative scaled coefficient value) are set to their minimum limit of the range. It is noted from Figure 8 that significantly higher cumulative gas production and gas water ratio and lower cumulative flowback water production is observed for the best case than those for the worst case. This observation is in line with what was observed previously regarding the impact of Pc on the cleanup, i.e., if Pc increases, more FF is retained within the matrix and consequently less FF flowback is produced and as a result GPL decreases. Another interesting observation is that the $\mathrm{V}$-shaped gas water ratio curve is observed for gas water ratio of the best case at early times as it was reported by $\mathrm{Xu}$ et al., (2016), i.e., a V-shaped trend caused by a gradual build-up of free gas in the fracture during the shut-in time could be noted.

\subsection{Two-Layer systems}

In this section, the results of layered systems with the cross-flow are presented to study the impact of layering and gravity in these sets.

From data of Figure 4 (Single-layer, set 1) and Figure 9 (Two-layer, set 42), it is noted that the two tornado charts look similar in terms of magnitude and trends of coefficients. The only difference is that the impact of gravity for the two-layer set under study has caused a decrease in the absolute value of the $\mathrm{K}_{\mathrm{f}}$ coefficient of the LRSM fitted to the total GPL only after 365 days of production. More interesting observations are evident if the gas production loss of individual layers is studied. It should be noted that decreases in the impact of a parameter in one layer will be accompanied by an increase in the impact of that parameter in the other layer such that the overall impact is what it is seen in Figure 9.

If we compare the Tornado charts of the top (Figure 10a) and bottom (Figure 10b) layers in the two-layer set, it is noted that in the top layer, layer 1, the fracture mobility coefficient (i.e. $\mathrm{K}_{\mathrm{f}}, \mathrm{K}_{\text {maxwf }}, \mathrm{n}_{\mathrm{wf}}, \mathrm{K}_{\text {maxgf }}$ and $\mathrm{n}_{\mathrm{gf}}$ ) are more important than the ones in the bottom layer especially after 365 days of production,. This trend is due to the fact that while injecting FF into the fracture, more FF goes to the bottom layer due to gravity making these parameters less 
important in the bottom layer (Figure 10b) (and as discussed below other parameters are more important). It should be noted that $\mathrm{K}_{\mathrm{f}}$ has two effects in this layered system: (1) increasing $\mathrm{K}_{\mathrm{f}}$ reduces GPL due to production enhancement in all layers (2) increasing $\mathrm{K}_{\mathrm{f}}$ causes more FF to travel from the top to bottom layer resulting in higher GPL values for the bottom layer. The result of these two effects causes the absolute value of the $\mathrm{K}_{\mathrm{f}}$ coefficient for the bottom layer to be less than the top layer. This reduction seems to be very significant such that the overall impact on total gas production loss is a reduction in the absolute value of $\mathrm{K}_{\mathrm{f}}$ as evident in Figure 4 and Figure 9 where single-layer and two-layer results are compared.

Data of Figure 10b also shows that the effect of Pc seems to be more important in the bottom layer as evident by the higher absolute value of coefficients for IFT and pore size distribution index $(\lambda)$. This is due to the fact that there is more FF in this layer as a result of FF gravity segregation. The absolute value of the $\mathrm{K}_{\mathrm{m}}$ coefficient is lower for the top layer. That is, the negative impact of an increase in $\mathrm{K}_{\mathrm{m}}$ that reduces Pc and increases GPL has reduced the positive impact of an increase in $\mathrm{K}_{\mathrm{m}}$ that improves mobility and reduces GPL. This is particularly evident after 365 days of production whereby the coefficient of $\mathrm{K}_{\mathrm{m}}$ is positive, i.e. an increase in $\mathrm{K}_{\mathrm{m}}$ increases GPL because it reduces Pc and less fluid is imbibed into the matrix rather than flowing down to the bottom layer. For the bottom layer the impact of how easy fluid flows into the matrix is more important and hence the coefficient of $\mathrm{K}_{\mathrm{m}}$ is negative.

For the Two-Layer Low DP set (set 43 with DP=100psi) and Two-Layer Extended Shut-in time (set 44 with ST=20days), the same observations as those of Two-Layer Base Reference set (set 42), described above, were noted.

For the Two-Layer Lower $\mathrm{K}_{\mathrm{m}}$ range and Extended Shut-in time (set 45 with $\mathrm{ST}=20$ days and $\mathrm{Kmr}=10$ ) also almost the same observations as what were reported above for set 42 are noted. The only difference here is that in the tornado chart of the bottom layer (Figure 11) we have a small positive coefficient value for $\mathrm{K}_{\mathrm{f}}$, i.e. the second effect of $\mathrm{K}_{\mathrm{f}}$ (increasing $\mathrm{K}_{\mathrm{f}}$ causes more FF travelling to the bottom layer and increases GPL in this layer) is more important. In other words, if the tornado charts of the bottom layer of the previous sets with the relevant top layer charts are compared, a reduction in the absolute value of $\mathrm{K}_{\mathrm{f}}$ coefficient is noted but the coefficient is negative indicating that an increase in $\mathrm{K}_{\mathrm{f}}$ reduces GPL due to improved fluid mobility in the fracture. However, in this set, the negative impact of the FF gravity segregation results in a positive $\mathrm{K}_{\mathrm{f}}$ coefficient in the bottom layer.

\subsubsection{Error Analysis Using Single/Two Layer sets}


The other reason to run the two-layer sets was to investigate how representative the single layer set results are for a layered system. In order to evaluate this, the behaviour of linear response surface functions, with interactive parameters (ILRSM), fitted to these data were studied. In this exercise, the predicted values by IRLSM fitted to single-layer and two-layer data were compared with the GPL values of the layered system obtained from our numerical simulation exercise referred to as true values.

The root mean square error, RMSE, Equation 7 and average absolute percentage deviation, $\mathrm{AAD} \%$, Equation 8, were used for this purpose with the results presented in Table 6.

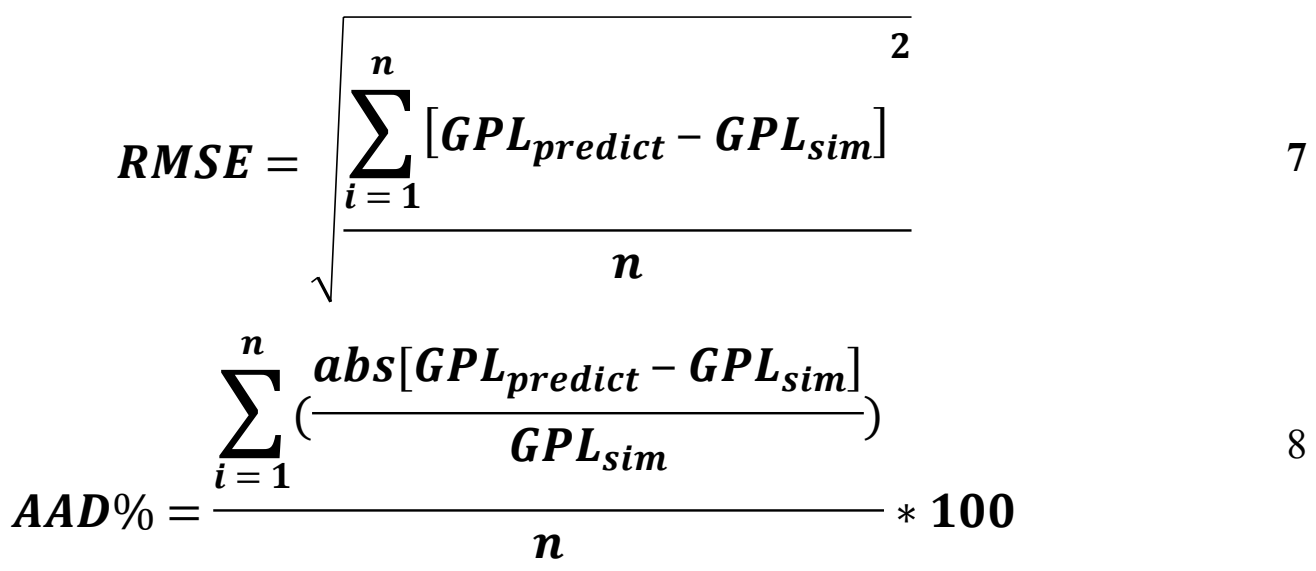

For AAD\% calculations, GPL results larger than 30\% was considered due to the fact that low true GPL values (in the denominator), causes exaggerated AAD\% values. Furthermore, such low GPL values are not of interest.

RMSE and also AAD\% in Table 6 show that ILRSM fitted to single layer data predicts the two-layer results with almost the same accuracy as that predicted by ILRSM fitted to the layered data. These data suggest that fitted ILRSM for single layer could be used to predict the GPL in layered systems, in other words, the impact of gravity segregation on the overall flowback cleanup efficiency is not insignificant.

\subsection{Cleanup with/without hysteresis effect}

During injection time in the hydraulically fracturing process, FF imbibes into the matrix through the fracture faces and then is partially produced with hydrocarbon fluid in a drainage process. Here, the capillary pressure and relative permeability hysteresis processes could play a role to control the clean-up of FF from the matrix invaded zone. 
In order to investigate the hysteresis effect, we benefited from available formulations in the literature relating the imbibition and drainage processes. Equations $9 \& 10$ describe the BrooksCorey drainage/imbibition capillary pressure curves respectively(Brooks and Corey, 1966).

$$
\begin{aligned}
& P_{c}=P_{d} *\left(\frac{S_{w}-S_{w r}}{1-S_{w r}}\right)^{-\frac{1}{\lambda}} \\
& P_{c}=P_{d} *\left[\left(\frac{S_{w}-S_{w r}}{1-S_{w r}-S_{n w r}}\right)^{-\frac{1}{\lambda}}-1\right]
\end{aligned}
$$

Equation Error! Reference source not found. is the rearranged form of Equation Error! Reference source not found., which has been used before in this study.

It is well documented that hysteresis of the wetting relative permeability is negligible, whereas hysteresis decreases the relative permeability to the non-wetting phase. In this set, for the case with hysteresis, the gas imbibition relative permeability Corey exponent, $\left(\mathrm{n}_{\mathrm{gm}}\right)_{\mathrm{imb}}$, in the matrix was set to 1.5 as minimum and 5 as maximum. In order to obtain the higher drainage relative

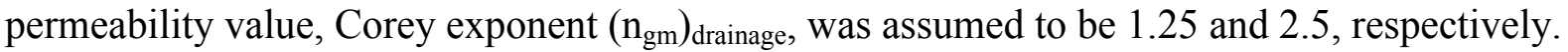
These values were considered based on the understanding of the process gained by the work of the GCR team, literature data and support of our sponsors of the project.

For the case without hysteresis, due to the fact that in the real case, imbibition process is dominant during injection time of the hydraulically fracturing process and a combination of drainage and imbibition process is happening during the production period, imbibition capillary pressure curve and imbibition relative permeability, $\left(\mathrm{n}_{\mathrm{gm}}\right)_{\mathrm{imb}}$, were used.

Comparing the tornado charts of the base reference set with hysteresis, set 47, (Figure 12a) and the base reference set without hysteresis, set 47, (Figure 12b), it is noted that the direction of impact of parameters and their magnitude are very similar. This indicates that considering hysteresis in this model does not change the tornado chart, in other words, the impact of considering hysteresis on the flowback cleanup performance is negligible.

Figure 13 compares the histogram charts of base reference set with and without hysteresis, showing that introducing hysteresis effect makes clean-up very slightly faster at all production periods. This is due to the fact that in the case without the hysteresis effect, lower imbibition gas relative permeability values have been used which results in lower gas production rate and slower clean-up.

\subsection{Sets with Increased Fracturing Fluid's Injection Volume (FVR=10)}


In high FVR sets, the ratio of the injected volume of FF to fracture volume (FVR) was increased from 2 in the base reference set to 10. As shown in the corresponding tornado chart of set 2 with only a higher FVR than the base reference set, Figure 14, the general trends of this high FVR set are similar to those of the reference set but with smaller coefficients (Figure 4). It is due to the fact that larger amount of injected FF requires a longer time to produce. Accordingly, compared to the base reference set, higher GPL is experienced as seen in the corresponding histogram chart of the GPL cumulative frequency, Figure 15. Quite interestingly, coefficients (Figure 14) and frequency of GPL (Figure 15) of this set after 370 days of production are similar to those of the base reference set after 30 days of production, Figure 4 and Figure 7. This implies higher injected FF only results in a delay in the cleanup process, in other words, increasing FVR from 2 to 10 significantly increased GPL and delayed fracture cleanup resulting in overall poorer and slower cleanup performance, Figure 15.

Comparing the tornado charts of the base reference sets and that of set 2 with higher FVR, Figure 4 and Figure 14 respectively, shows that the relative importance of pertinent parameters when $\mathrm{FVR}=10$ was less than those when $\mathrm{FVR}=2$, especially at higher production periods.

The negative impact of larger amount of injected FF can clearly be seen in Figure 16a which shows the water saturation map of the best case after two days of a shut-in. Comparing data of this Figure with those of Figure 5 in the base reference set, it is noted that the FF saturation in the matrix and fracture is much greater than that of the base case. Similarly, the FF saturation in the matrix and fracture in the worst case, Figure 17, is much higher than that of the base case, Figure 6. . As detailed elsewhere (Nasriani and Jamiolahmady, 2018) to have a better visualisation of the saturation distribution, dimensions of grid blocks have not been selected to the same scale as those of the well model under study.

20 additional sets, with a total of 81,920 simulation runs are also performed. These sets include studying the impact of a combination of increasing fracture volume ratio (FVR) with prolonging shut-in time, reducing matrix permeability range and decreasing or increasing DP on GPL in long fracture sets $(\mathrm{Xf}=400 \mathrm{~m})$ and short fracture sets $(\mathrm{Xf}=100 \mathrm{~m})$. The long sets are sets 9 and 29 to 41 and the short sets are sets 11,20 and 49 to 54 .

In summary, the main observations were that injecting a high volume of $\mathrm{FF}, \mathrm{FVR}=10$, into a very tight formation significantly impaired production. The effect of varying other parameters such as extending soaking time or increasing pressure drawdown significantly reduced the negative impact of high FVR resulting in less GPL reduction. 
In the case of sets 38 to 41 with the very tight formation, high FVR resulted in inconsistencies in the results because of high GPL close or equal to $100 \%$, which resulted in killing the well. The common characteristic between sets 38, 39, 40 and 41 is that they all include very tight formations $\left(\mathrm{K}_{\mathrm{m}}=0.01-1 \mu \mathrm{D}\right)$. In Figure 18 , it is noted that as the matrix permeability range is reduced by a factor of a 100 (relative to the base reference set) in these sets, the tornado chart results (Figure 18) are significantly impaired, rendering comparison of pertinent parameters across sets unfeasible, as the parameter effects are masked by the high FVR damage.

In set 38 , the histogram chart of the GPL cumulative frequency, Figure 19, shows that $54 \%$ of simulated runs (2212 out of 4096) have a GPL greater than $90 \%$ after one year of production. Similar results for set 39, 50\% (2048 out of 4096), have a GPL greater than 90\% after one year of production. set 40 and 41 show similar results with 51\% (2089 out of 4096) and 54\% (2212 out of 4096), respectively, having a GPL greater than $90 \%$ after one year of production. That is, the majority of runs in these very tight formation sets have exceptionally high GPL which results in a poor response surface model and consequently a less reliable tornado chart. In other words, once a high volume of fracturing fluid is injected into the tight formation, the well is effectively killed.

The effect of varying other parameters such as extending ST or increasing DP provides no major differences as excessive FF has been injected into a very low permeability formation. Therefore, it can be concluded that it is inadvisable to inject too much FF, particularly in tight formations as gas production is significantly impaired.

In short fractured wells and in line with what was observed in long fracture sets, increased FVR from 2 to 10 lead to increased GPL and poor cleanup efficiency, mainly due to the more FF invasion. Furthermore, when FVR was increased from 2 to 10 in short fractures, the parameters related to Pc became less important for the sets with a higher FVR. For both long and short fracture sets, it was observed that high DP ( $\Delta \mathrm{P}=4000 \mathrm{psi})$ leads to an enhancement of the cleanup performance, reducing GPL and consequently, obtaining a greater production than in low drawdown sets. In tight formations, comparing short and long fractured wells using an FVR of 10, it was found that the effect of an increased FVR has a greater impact on GPL in short fractures at early times than in long fractures, being the other way around at later stages. IFT and ngf showed consistently greater values for long fractures. If an extended ST was applied when using an increased FVR of 10, the results obtained for both (with and without 
increased ST) were, in some manner, the same, not improving GPL. However the parameters related to Pc had a greater impact after applying an extended ST.

\subsection{Sets with Larger Initial Water Saturation}

In two new sets, initial water saturation (Swi) was increased from $15 \%$ in the base reference set, set 1 , to $50 \%$ in set 62 and $75 \%$ in set 63 . In all sets, irreducible water saturation $\left(\mathrm{S}_{\mathrm{wir}}\right)$, as well as critical water saturation (Swc), were set to $15 \%$, consequently, formation water was immobile in set 1 and mobile in sets 62 and 63 .

Comparing the tornado chart of these three sets $1,62 \& 63$, Figure 4, Figure $20 \&$ Figure 21 respectively, with each other, it is noted that the observed trends of all parameters in sets 1 and 62 are more or less the same, but the value of some of the parameters are slightly different. The main difference between trends in these two sets compared to the set 63 with the highest Swi is that $\mathrm{Kf}$ is the most important parameter in sets 1 and 62 and second most important parameter after ngm in set 63 . In set 63 , due to the fact that formation water saturation is set to the largest value ( $\mathrm{Swi}=75 \%$ ), gas mobility in the matrix is the most critical parameter, in other words, ngm is the main controlling parameter on GPL. For the same reason, ngf/nwf is more/less important in sets 62 and 63 compared to those of set 1.

If one compares Pc pertinent parameters (IFT, $\lambda$ and $\mathrm{K}_{\mathrm{m}}$ ) in set 1 and 62 , it is noted that the effect of Pc on GPL is less important in set 62 due to smaller absolute values for IFT and $\lambda$, i.e. keeping water in the matrix, due to its high water saturation, is not as important in improving the cleanup efficiency.

The other important observation in Figure 21 is the trend change in the IFT coefficient in set 63 . That is, in this set 63, IFT has a positive value indicating that an increase in IFT increases GPL. However, it should be noted that IFT is not the only parameter affecting Pc, hence, we need to see the effect of IFT, $K_{m}$ and $\lambda$ all together to understand the effect of Pc on cleanup efficiency in this largest Swi set. In this sets, the capillary pressure was calculated and plotted by selecting the corresponding values of IFT, $\mathrm{K}_{\mathrm{m}}$ and $\lambda$ for best and worst cases from their relevant tornado charts and also using Equations 6 and 7.

Figure 22 shows that in set 63 , Pc of the worst case is higher than the best case whilst in sets 1 and 62 Pc of the worst case is lower than the best case at all Sw. In other words, in set 1 and set 62, it was better to keep the FF in the matrix by having higher Pc, but in set 63, it was better to backflow the FF out of the matrix. This is due to large initial water saturation, which has a 
detrimental effect on gas production especially noting that initial gas saturation is $25 \%$, which is close to the residual trap gas saturation value of $10 \%$.

Therefore, in set 63, unlike previous two sets (1 and 62), using chemicals (IFT reducing agents) to reduce Pc could reduce GPL and improve cleanup efficiency. Figure 23 shows the histogram chart that compares the GPL cumulative frequency of the runs in sets 1, 62 and 63 . Slower/slowest cleanup is observed for sets 62 and 63 with larger/largest initial water saturation due to the detrimental effect of mobile water on gas production.

\section{Conclusions}

An extensive investigation on the cleanup efficiency of fractured wells was conducted to further improve the current understanding of hydraulic fracturing treatment for practical field applications.

In this study, the results of 32 different sets were discussed including the following sets:

- Long fracture $(400 \mathrm{~m})$ base reference set (1 sets)

- Two-layer long fracture sets (4 sets)

- Long fracture sets with/without hysteresis (2 sets)

- Long fracture sets(400m) with high FF injection volume (15 sets)

- Short fracture set $(100 \mathrm{~m})$ with high FF injection volume, (8 sets)

- Long fracture sets with initial mobile water saturation (2 sets)

The results have been compared with those of a base reference set and other similar sets. These numerical models have similar geometry as those of the base reference set but are different in the shut-in time period (ST), matrix permeability variation range, pressure drawdown (DP) and length of the hydraulic fracture.

A summary of the key conclusions is given below:

1. Fracture permeability (Kf), as well as FF flowback mobility pertinent parameters within the fracture, were the key drivers of GPL improvement for all cases studied apart from sets with very low $\mathrm{K}_{\mathrm{m}}$ range, sets with very low $\mathrm{K}_{\mathrm{m}}$ range and low DP and sets with high Swi.

2. Additionally, matrix permeability $\left(\mathrm{K}_{\mathrm{m}}\right)$ displayed a positive impact on GPL, i.e. an increase in $\mathrm{K}_{\mathrm{m}}$ reduced GPL and improved fracture cleanup, for all sets. 
3. The coefficients of interfacial tension (IFT) and pore size index $(\lambda)$ parameters controlling capillary pressure indicated that an improvement of cleanup efficiency is attained when capillary pressure $(\mathrm{Pc})$ is increased.

- This is achieved when IFT is increased and/or $\lambda$ is decreased except for sets with a very low $K_{m}$ range and or the set with high Swi (set 63).

4. The impact of considering hysteresis was negligible.

5. In layered systems, $\mathrm{K}_{\mathrm{f}}$ had two effects: (1) increasing $\mathrm{K}_{\mathrm{f}}$ reduces GPL due to production enhancement in all layers (2) increasing $\mathrm{K}_{\mathrm{f}}$ caused more FF to travel from the top to bottom layer resulting in higher GPL values for the bottom layer.

- The impact of gravity in the two-layer sets caused a decrease in the absolute value of the negative $\mathrm{Kf}$ coefficient (i.e., first effect was still dominant). Generally, the result of these two opposing effects caused the absolute value of the $\mathrm{K}_{\mathrm{f}}$ coefficient for the bottom layer to be less than the top layer. Additionally, in layered sets 42 (base reference set), $43(\mathrm{DP}=100)$ and 44 $(\mathrm{ST}=20)$, the first effect of $\mathrm{K}_{\mathrm{f}}$ on GPL was dominant in the bottom layer. However, in set $45(\mathrm{Kmr}=10$ and $\mathrm{ST}=20)$ the second effect (more FF travels to bottom layer causing more GPL) was dominant resulting in a positive value for $\mathrm{K}_{\mathrm{f}}$.

6. In two-layer sets, it was noted that in the top layer, layer 1, the fracture mobility coefficients (i.e. $\mathrm{K}_{\mathrm{f}}, \mathrm{K}_{\text {maxwf }}, \mathrm{n}_{\mathrm{wf}}, \mathrm{K}_{\text {maxgf }}$ and $\mathrm{n}_{\mathrm{gf}}$ ) were more important than the ones in the bottom layer.

7. In layered sets, the effect of Pc seemed to be more important in the bottom layer as evident by the higher absolute value of coefficients for IFT and pore size distribution index $(\lambda)$ due to having more FF in this layer.

8. RMSE and also AAD\% results showed that ILRSM fitted to the single layer simulation data predicted the two-layer results with almost the same accuracy as that predicted by ILRSM fitted to layered data. These data suggested that fitted ILRSM to the single layer can be used to predict the GPL in layered systems.

9. Increasing FVR from 2 to 10 significantly increased GPL and delayed fracture cleanup resulting in overall poorer cleanup performance.

10. The relative importance of pertinent parameters when $F V R=10$ was less than those when FVR=2, especially at higher production periods. 


\section{Acknowledgements}

The above study was conducted as a part of the Gas-condensate Recovery Project at HeriotWatt University. This research project is sponsored by Daikin, DongEnergy, Ecopetrol/Equion, ExxonMobil, GDF, INPEX, JX-Nippon, Petrobras, RWE, Saudi-Aramco and TOTAL, whose contribution is gratefully acknowledged.

\section{Nomenclature}

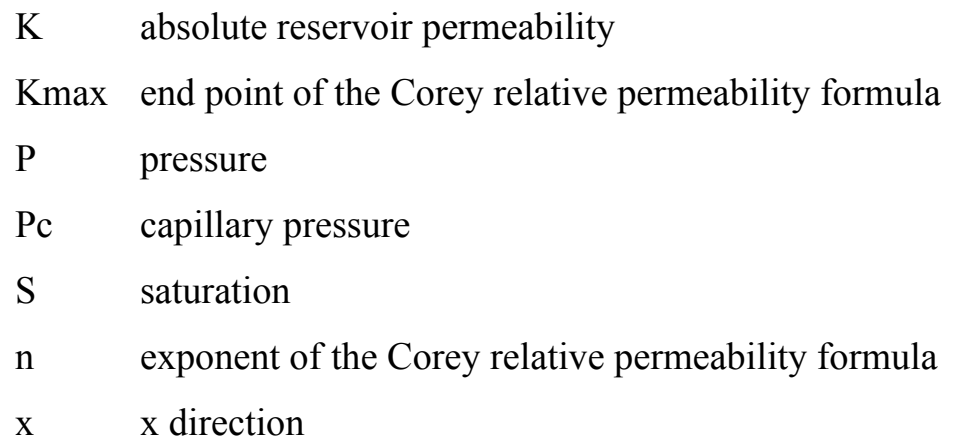


y y direction

z $\quad \mathrm{z}$ direction

\section{Subscript}

$\begin{array}{ll}\mathrm{g} & \text { gas } \\ \mathrm{w} & \text { water } \\ \mathrm{r} & \text { residual } \\ \mathrm{f} & \text { fracture } \\ \mathrm{m} & \text { matrix }\end{array}$

\section{Abbreviations}

LRSM linear response surface model

ILRSM linear response surface model with interaction

FVR the ratio of injected fracture fluid to fracture volume

IFT interfacial tension

FF fracture fluid

DP Pressure drawdown

GPL gas production loss

$\mathrm{Kmr}$ Matrix Permeability Ratio, i.e., if $\mathrm{Kmr}=10$ mean the $\mathrm{Km}$ variation range is reduced by factor of 10

ST Shut-in/Soaking time

VW Vertical Well

HF Hydraulic Fracturing

\section{References}

Agrawal, S. and Sharma, M. M. (2015) 'Practical insights into liquid loading within hydraulic fractures and potential unconventional gas reservoir optimization strategies', Journal of Unconventional Oil and Gas Resources. Elsevier Ltd, 11, pp. 60-74. doi: 10.1016/j.juogr.2015.04.001.

Ahmed, U., Abou-Sayed, A. s. and Jones, A. H. (1979) 'EXPERIMENTAL EVALUATION OF FRACTURING FLUID INTERACTION WITH TIGHT RESERVOIR ROCKS AND PROPPED FRACTURES.', in SPE (Soc of Pet Eng) - AIME Symp on Low Permeability Gas Reservoirs, pp. 109-126. Available at: https://www.scopus.com/inward/record.uri?eid=2-s2.00018298539\&partnerID=40\&md5=231950434036debbc591942ed57027d9.

Alajmi, S. E. (2012) Modelling of gas-condensate flow around complex well geometries and cleanup efficiency in heterogeneous systems. Heriot-Watt University. 
Bazin, B., Bekri, S., Vizika, O., Herzhaft, B. and Aubry, E. (2010) 'Fracturing in Tight Gas Reservoirs: Application of Special-Core-Analysis Methods To Investigate Formation-Damage Mechanisms'. Society of Petroleum Engineers. doi: 10.2118/112460-PA.

Bennion, D. B., Thomas, F. B. and Ma, T. (2000) 'Recent Advances in Laboratory Test Protocols to Evaluate Optimum Drilling, Completion and Stimulation Practices for Low Permeability Gas Reservoirs'. Society of Petroleum Engineers. doi: 10.2118/60324-MS.

Brooks, R. H. and Corey, A. T. (1966) 'Properties of porous media affecting fluid flow', Journal of the Irrigation and Drainage Division, 92(2), pp. 61-90.

Cheng, Y. (2012) 'Impact of water dynamics in fractures on the performance of hydraulically fractured wells in gas-shale reservoirs', Journal of Canadian Petroleum Technology. Society of Petroleum Engineers, 51(2), pp. 143-151.

Cooke Jr., C. E. and C.E., C. (1973) 'Conductivity of Fracture Proppants in Multiple Layers', Journal of Petroleum Technology. Society of Petroleum Engineers, 25(9), pp. 1101-1107. doi: 10.2118/4117-PA.

Cooke Jr., C. E. and Cooke, C. E. J. (1975) 'Effect of Fracturing Fluids on Fracture Conductivity', Spe. Society of Petroleum Engineers, pp. 1273-1282. doi: 10.2118/5114-PA.

Fu, Y., Dehghanpour, H., Ezulike, D. O. and Jones Jr., R. S. (2017) 'Estimating Effective Fracture Pore Volume From Flowback Data and Evaluating Its Relationship to Design Parameters of Multistage-Fracture Completion'. Society of Petroleum Engineers. doi: 10.2118/175892-PA.

Gdanski, R. D. and Walters, H. G. (2010) 'Impact of Fracture Conductivity and Matrix Relative Permeability on Load Recovery'. Society of Petroleum Engineers. doi: 10.2118/133057-MS. Ghahri, P. (2010) Modelling of Gas-condensate flow around horizontal and deviated wells and cleanup efficiency of hydraulically fractured wells. Heriot-Watt University. Available at: http://www.ros.hw.ac.uk/handle/10399/2354.

Ghahri, P., Jamiolahmady, M. and Sohrabi, M. (2009) 'Investigation of cleanup efficiency of hydraulically fractured wells in gas condensate reservoirs', in 8th European Formation Damage Conference 2009 - New Technologies for Conventional and Unconventional Reservoirs, pp. 537-551. Available at: https://www.scopus.com/inward/record.uri?eid=2-s2.070449466268\&partnerID=40\&md5=ba96103746bdd371bdbfc066e58c7b22.

Ghahri, P., Jamiolahmady, M. and Sohrabi, M. (2011a) 'SPE 144114 A Thorough Investigation Of Cleanup Efficiency Of Hydraulic Fractured Wells Using Response Surface Methodology', (1979). doi: 10.2118/144114-MS. 
Ghahri, P., Jamiolahmady, M. and Sohrabi, M. (2011b) 'SPE 144114 A Thorough Investigation Of Cleanup Efficiency Of Hydraulic Fractured Wells Using Response Surface Methodology'. Society of Petroleum Engineers. doi: 10.2118/144114-MS.

Ghanbari, E. and Dehghanpour, H. (2016) 'The fate of fracturing water : A field and simulation study', FUEL. Elsevier Ltd, 163, pp. 282-294. doi: 10.1016/j.fuel.2015.09.040.

Jamiolahmady, M., Alajmi, E., Nasriani, H. R., Ghahri, P. and Pichestapong, K. (2014) 'A Thorough Investigation of Clean-up Efficiency of Hydraulic Fractured Wells Using Statistical Approaches', SPE Annual Technical Conference and Exhibition, 27-29 October. . Amsterdam; The Netherlands. doi: 10.2118/170862-MS.

Jamiolahmady, M., Sohrabi, M. and Ghahri, P. (2009) 'Investigation of Cleanup Efficiency of Hydraulically Fractured Wells in Gas Condensate Reservoirs'. Society of Petroleum Engineers. doi: 10.2118/121916-MS.

Joshi, S., Sherali, H. D. and Tew, J. D. (1998) 'An enhanced response surface methodology (RSM) algorithm using gradient deflection and second-order search strategies', Computers \& Operations Research, 25(7-8), pp. 531-541. doi: 10.1016/S0305-0548(98)00014-8.

Lai, F., Li, Z. and Wang, Y. (2017) 'Impact of water blocking in fractures on the performance of hydraulically fractured horizontal wells in tight gas reservoir', Journal of Petroleum Science and Engineering. Elsevier Ltd, 156(May), pp. 134-141. doi: 10.1016/j.petrol.2017.05.002.

Mahadevan, J. and Sharma, M. M. (2005) 'Factors affecting cleanup of water blocks: A laboratory investigation', SPE Journal, 10(3), pp. 238-246. Available at: https://www.scopus.com/inward/record.uri?eid=2-s2.0-

26844544500\&partnerID=40\&md5=bc8872eeaa64a7b1afa9ac681e3728cf.

Montgomery, K. T., Holditch, S. A. and Berthelot, J. M. (1990) 'Effects of fracture fluid invasion on cleanup behavior and pressure buildup analysis', in Proceedings - SPE Annual Technical Conference and Exhibition, pp. 279-290. Available at: https://www.scopus.com/inward/record.uri?eid=2-s2.0-

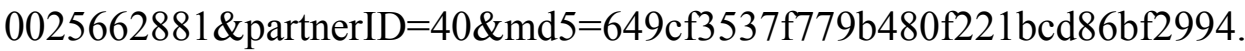

Nasriani, H. R. and Jamiolahmady, M. (2018) 'Maximizing fracture productivity in unconventional fields; analysis of post hydraulic fracturing flowback cleanup', Journal of Natural Gas Science and Engineering. Elsevier, 52(September 2017), p. doi: https://doi.org/10.1016/j.jngse.2018.01.045.

Nasriani, H. R., Jamiolahmady, M. and Alajmi, E. (2014a) 'An integrated study of cleanup efficiency of short hydraulic fractured vertical wells using response surface methodology', in 
76th European Association of Geoscientists and Engineers Conference and Exhibition 2014: Experience the Energy - Incorporating SPE EUROPEC 2014. doi: 10.3997/22144609.20141380.

Nasriani, H. R., Jamiolahmady, M. and Alajmi, E. (2014b) 'An Integrated Study of Cleanup Efficiency of Short Hydraulic Fractured Vertical Wells Using Response Surface Methodology', in 76th EAGE Conference and Exhibition 2014. doi: 10.3997/22144609.20141380.

Nasriani, H. R., Jamiolahmady, M., Alajmi, E. and Ghahri, P. (2014) 'A study of hydraulic fracturing clean-up efficiency in unconventional gas reservoirs using statistical approaches', in 14th European Conference on the Mathematics of Oil Recovery 2014, ECMOR 2014.

Nasriani, H. R., Jamiolahmady, M., Alajmi, E. and Ghahri, P. (2014) 'A Study of Hydraulic Fracturing Clean-up Efficiency in Unconventional Gas Reservoirs Using Statistical Approaches', in ECMOR XIV-14th European Conference on the Mathematics of Oil Recovery. Schlumberger (2015) 'Geoquest, ECLIPSE 100, Version 2015.1.0.0', Simulation Launch Management Utility.

Tannich, J. D. (1975) 'Liquid Removal From Hydraulically Fractured Gas Wells', Journal of Petroleum Technology, 27(11). doi: 10.2118/5113-PA.

Thomas, L. K., Katz, D. L. and Tek, M. R. (1968) 'Threshold pressure phenomena in porous media', Society of Petroleum Engineers Journal. Society of Petroleum Engineers, 8(2), pp. 174-184.

Wang, M. and Leung, J. Y. (2016) 'Numerical Investigation of Coupling Multiphase Flow and Geomechanical Effects on Water Loss During Hydraulic-Fracturing Flowback Operation'. Society of Petroleum Engineers. doi: 10.2118/178618-PA.

Xu, Y., Ade, O. and Dehghanpour, H. (2016) 'Journal of Petroleum Science and Engineering A fl owing material balance equation for two-phase fl owback analysis', 142, pp. 170-185. doi: 10.1016/j.petrol.2016.01.018.

Zhou, Q., Dilmore, R., Kleit, A. and Wang, J. Y. (2016) 'Evaluating Fracture-Fluid Flowback in Marcellus Using Data-Mining Technologies'. Society of Petroleum Engineers. doi: 10.2118/173364-PA. 


\section{Tables}

Table 1 Basic properties of the (Xf is fracture half length) model

\begin{tabular}{|c|c|c|c|c|}
\hline $\mathbf{X}_{\mathbf{f}}(\mathbf{m})$ & $\mathbf{w}_{\mathbf{f}}(\mathbf{m})$ & $\mathbf{X r e s}(\mathbf{m})$ & $\operatorname{Yres}(\mathbf{m})$ & $\operatorname{Zres}(\mathbf{m})$ \\
\hline 100 or 400 & 0.004 & 2000 & 2000 & 40 \\
\hline
\end{tabular}

Table 2 Fluid properties of gas used in this study.

\begin{tabular}{|c|c|c|}
\hline $\mathbf{P}(\mathbf{p s i})$ & Bg & $\mu(c p)$ \\
\hline 14.65 & 260.21 & 0.0147 \\
\hline 400 & 9.4295 & 0.0149 \\
\hline 600 & 6.2505 & 0.015 \\
\hline 800 & 4.6658 & 0.0152 \\
\hline 1000 & 3.7189 & 0.0154 \\
\hline 1500 & 2.4673 & 0.016 \\
\hline 2000 & 1.8527 & 0.0168 \\
\hline 2500 & 1.492 & 0.0177 \\
\hline 3000 & 1.2574 & 0.0187 \\
\hline 3500 & 1.0942 & 0.0198 \\
\hline 4000 & 0.9749 & 0.021 \\
\hline 5000 & 0.8137 & 0.0235 \\
\hline 6000 & 0.7109 & 0.026 \\
\hline 7000 & 0.6401 & 0.0283 \\
\hline 7500 & 0.6124 & 0.0295 \\
\hline 8000 & 0.5886 & 0.0306 \\
\hline 8500 & 0.5677 & 0.0317 \\
\hline & & \\
\hline
\end{tabular}


Table 3 The range of variation of uncertain parameters after fracturing.

\begin{tabular}{|c|c|c|c|}
\hline & Parameter & Min & Max \\
\hline Fracture Permeability & $\mathrm{K}_{\mathrm{f}}(\mathrm{D})$ & 1 & 30 \\
\hline Matrix Permeability & $\mathrm{K}_{\mathrm{m}}$ & $1 \mu \mathrm{D}$ & $100 \mu \mathrm{D}$ \\
\hline Matrix capillary pressure curve (Pc) & Pore size index $\lambda$ & 1 & 4 \\
\hline Matrix capillary pressure curve (Pc) & Threshold pressure & Eq. (11) & Eq. (11) \\
\hline Matrix capillary pressure curve (Pc) & $\begin{array}{l}\text { Interfacial Tension } \\
\qquad(\mathrm{mNm} / \mathrm{m})\end{array}$ & 2 & 50 \\
\hline Matrix Krg curve & $\mathrm{n}_{\mathrm{gm}}$ & 1.5 & 5 \\
\hline Matrix Krw curve & $\mathrm{n}_{\mathrm{wm}}$ & 1.2 & 4 \\
\hline Matrix Krg curve & $\mathrm{K}_{\operatorname{maxg}}($ end point $)$ & 0.5 & 1.0 \\
\hline Matrix Krw curve & $\mathrm{K}_{\operatorname{maxw}}($ end point $)$ & 0.05 & 0.6 \\
\hline Fracture Krg curve & $\mathrm{n}_{\mathrm{gf}}$ & 1.5 & 5 \\
\hline Fracture Krw curve & $\mathrm{n}_{\mathrm{wf}}$ & 1.2 & 4 \\
\hline Fracture Krg curve & $\mathrm{K}_{\operatorname{maxg}}($ end point $)$ & 0.5 & 1.0 \\
\hline Fracture Krw curve & $\mathrm{K}_{\operatorname{maxw}}($ end point $)$ & 0.1 & 0.75 \\
\hline Pressure Drawdown & $\Delta p($ psi) & 1000 & 1000 \\
\hline Porosity & $\phi$ & 0.15 & 0.15 \\
\hline Matrix Krg curve & $\mathrm{S}_{\mathrm{grm}}$ & 0.1 & 0.1 \\
\hline Matrix Krw curve & $\mathrm{S}_{\mathrm{wrm}}$ & 0.15 & 0.15 \\
\hline Fracture Krg curve & $\mathrm{S}_{\mathrm{grf}}$ & 0.1 & 0.1 \\
\hline Fracture Krw curve & $\mathrm{S}_{\mathrm{wrf}}$ & 0.15 & 0.15 \\
\hline Initial pre & ies of the model & & \\
\hline $\begin{array}{l}\text { Initial water saturation within the } \\
\text { matrix and fracture }\end{array}$ & \multicolumn{3}{|c|}{$15 \%$} \\
\hline $\begin{array}{l}\text { Initial gas saturation within the } \\
\text { matrix and fracture }\end{array}$ & \multicolumn{3}{|c|}{$85 \%$} \\
\hline
\end{tabular}


Table 4a Sets analysed

\begin{tabular}{|c|c|c|c|c|c|c|c|c|c|c|c|c|c|c|c|c|}
\hline 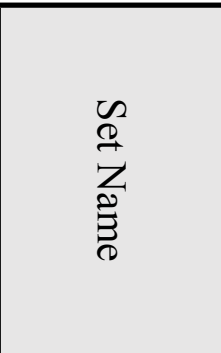 & $\begin{array}{l}\underset{\sigma}{\ominus} \\
\underset{\theta}{\theta} \\
\underbrace{}\end{array}$ & $\sum_{0}^{T}$ & 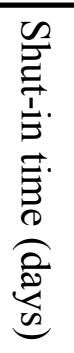 & 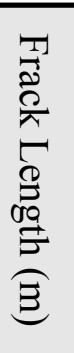 & 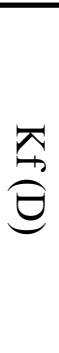 & $\stackrel{\widetilde{\Xi}}{\underset{\Xi}{\Xi}}$ & $\overline{\tilde{\Xi}}$ & 羿 & $\stackrel{g}{g}$ & 离 & 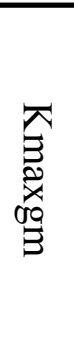 & 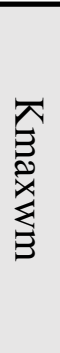 & $\stackrel{\vec{g}}{\stackrel{g}{\rightarrow}}$ & $\underset{\infty}{\Xi}$ & 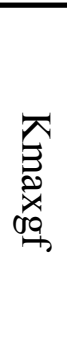 & 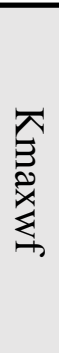 \\
\hline $\begin{array}{l}\text { Default } \\
\text { Values }\end{array}$ & $\overline{8}$ & $N$ & $N$ & $\stackrel{8}{8}$ & : & $\stackrel{5}{8}$ & $\vec{t}$ & $\begin{array}{l}n \\
\ddot{o}\end{array}$ & í & $\dot{\bar{n}}$ & i & $\begin{array}{l}0 \\
\dot{0} \\
\text { ú } \\
0 \\
0\end{array}$ & 宛 & $\stackrel{\sim}{\grave{n}}$ & í & $\begin{array}{l}0 \\
\dot{0} \\
\dot{0} \\
\text { ur }\end{array}$ \\
\hline SFVW-Set 1 & $\checkmark$ & $\checkmark$ & $\checkmark$ & $\checkmark$ & $\checkmark$ & $\checkmark$ & $\checkmark$ & $\checkmark$ & $\checkmark$ & $\checkmark$ & $\checkmark$ & $\checkmark$ & $\checkmark$ & $\checkmark$ & $\checkmark$ & $\checkmark$ \\
\hline SFVW-Set 2 & $\checkmark$ & 10 & $\checkmark$ & $\checkmark$ & $\checkmark$ & $\checkmark$ & $\checkmark$ & $\checkmark$ & $\checkmark$ & $\checkmark$ & $\checkmark$ & $\checkmark$ & $\checkmark$ & $\checkmark$ & $\checkmark$ & $\checkmark$ \\
\hline SFVW-Set 9 & $\checkmark$ & 5 & $\checkmark$ & $\checkmark$ & $\checkmark$ & $\checkmark$ & $\checkmark$ & $\checkmark$ & $\checkmark$ & $\checkmark$ & $\checkmark$ & $\checkmark$ & $\checkmark$ & $\checkmark$ & $\checkmark$ & $\checkmark$ \\
\hline $\begin{array}{c}\text { SFVW-Set } \\
11\end{array}$ & $\checkmark$ & 5 & $\checkmark$ & $\begin{array}{c}10 \\
0\end{array}$ & $\checkmark$ & $\checkmark$ & $\checkmark$ & $\checkmark$ & $\checkmark$ & $\checkmark$ & $\checkmark$ & $\checkmark$ & $\checkmark$ & $\checkmark$ & $\checkmark$ & $\checkmark$ \\
\hline $\begin{array}{c}\text { SFVW-Set } \\
20 \\
\end{array}$ & $\checkmark$ & 10 & $\checkmark$ & $\begin{array}{c}10 \\
0\end{array}$ & $\checkmark$ & $\checkmark$ & $\checkmark$ & $\checkmark$ & $\checkmark$ & $\checkmark$ & $\checkmark$ & $\checkmark$ & $\checkmark$ & $\checkmark$ & $\checkmark$ & $\checkmark$ \\
\hline $\begin{array}{c}\text { SFVW-Set } \\
29\end{array}$ & $<$ & 10 & 20 & $\checkmark$ & $\checkmark$ & $<$ & $\checkmark$ & $\checkmark$ & $\checkmark$ & $\checkmark$ & $\checkmark$ & $\checkmark$ & $\checkmark$ & $\checkmark$ & $\checkmark$ & $\checkmark$ \\
\hline $\begin{array}{c}\text { SFVW-Set } \\
30\end{array}$ & $\begin{array}{c}10 \\
0\end{array}$ & 10 & 20 & $\checkmark$ & $\checkmark$ & $\checkmark$ & $\checkmark$ & $\checkmark$ & $\checkmark$ & $\checkmark$ & $\checkmark$ & $\checkmark$ & $\checkmark$ & $\checkmark$ & $\checkmark$ & $\checkmark$ \\
\hline $\begin{array}{c}\text { SFVW-Set } \\
31\end{array}$ & 응 & 10 & 20 & $\checkmark$ & $\checkmark$ & $\checkmark$ & $\checkmark$ & $\checkmark$ & $\checkmark$ & $\checkmark$ & $\checkmark$ & $\checkmark$ & $\checkmark$ & $\checkmark$ & $\checkmark$ & $\checkmark$ \\
\hline $\begin{array}{c}\text { SFVW-Set } \\
32\end{array}$ & ம & 10 & $\checkmark$ & $\checkmark$ & $\checkmark$ & $\checkmark$ & $\checkmark$ & $\checkmark$ & $\checkmark$ & $\checkmark$ & $\checkmark$ & $\checkmark$ & $\checkmark$ & $\checkmark$ & $\checkmark$ & $\checkmark$ \\
\hline $\begin{array}{c}\text { SFVW-Set } \\
33\end{array}$ & 응 & 10 & $\checkmark$ & $\checkmark$ & $\checkmark$ & $\checkmark$ & $\checkmark$ & $\checkmark$ & $\checkmark$ & $\checkmark$ & $\checkmark$ & $\checkmark$ & $\checkmark$ & $\checkmark$ & $\checkmark$ & $\checkmark$ \\
\hline $\begin{array}{c}\text { SFVW-Set } \\
34\end{array}$ & $<$ & 10 & 20 & $\checkmark$ & $\checkmark$ & $\begin{array}{l}0 \\
ن \\
ن \\
\dot{1} \\
0\end{array}$ & $\checkmark$ & $\checkmark$ & $\checkmark$ & $\checkmark$ & $\checkmark$ & $\checkmark$ & $\checkmark$ & $\checkmark$ & $\checkmark$ & $\checkmark$ \\
\hline $\begin{array}{c}\text { SFVW-Set } \\
35\end{array}$ & $\checkmark$ & 10 & $\checkmark$ & $\checkmark$ & $\checkmark$ & $\begin{array}{l}0 \\
\dot{1} \\
1 \\
0 \\
0\end{array}$ & $\checkmark$ & $\checkmark$ & $\checkmark$ & $\checkmark$ & $\checkmark$ & $\checkmark$ & $\checkmark$ & $\checkmark$ & $\checkmark$ & $\checkmark$ \\
\hline $\begin{array}{c}\text { SFVW-Set } \\
36\end{array}$ & $\begin{array}{l}\text { 응 } \\
\text { 응 }\end{array}$ & 10 & 20 & $\checkmark$ & $\checkmark$ & $\begin{array}{l}0 \\
\dot{1} \\
\stackrel{1}{\bullet} \\
0\end{array}$ & $\checkmark$ & $\checkmark$ & $\checkmark$ & $\checkmark$ & $\checkmark$ & $\checkmark$ & $\checkmark$ & $\checkmark$ & $\checkmark$ & $\checkmark$ \\
\hline
\end{tabular}


Table 4b Sets analysed

\begin{tabular}{|c|c|c|c|c|c|c|c|c|c|c|c|c|c|c|c|c|}
\hline 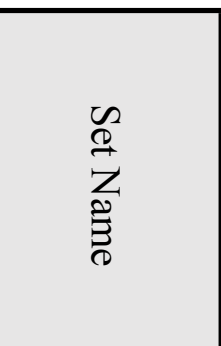 & 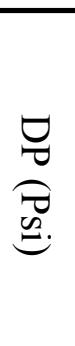 & $\sum_{\lambda}^{\pi}$ & 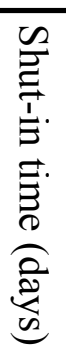 & 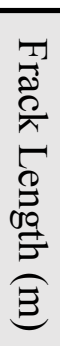 & 㞣 & 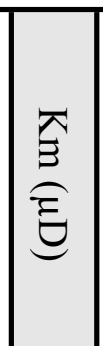 & $\stackrel{\vec{\partial}}{\vec{\Xi}}$ & 雬 & 舀 & $\underset{\Xi}{\Xi}$ & 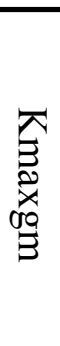 & 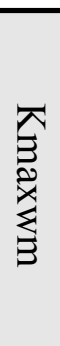 & 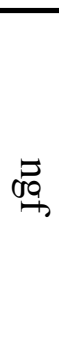 & $\underset{\text { ¿ }}{\rightleftarrows}$ & 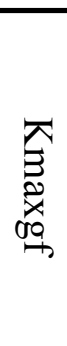 & 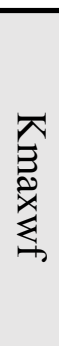 \\
\hline $\begin{array}{l}\text { Default } \\
\text { Values }\end{array}$ & $\overline{8}$ & $N$ & $N$ & $\stackrel{8}{8}$ & ì & $\frac{7}{8}$ & $\vec{b}$ & $\begin{array}{l}\text { '́n } \\
\stackrel{y}{0}\end{array}$ & $\bar{u}$ & $\ddot{i}$ & $\begin{array}{l}0 \\
\text { î } \\
1\end{array}$ & $\begin{array}{l}0 \\
0 \\
0 \\
1 \\
0 \\
0\end{array}$ & 它 & $\ddot{\tilde{n}}$ & $\begin{array}{l}0 \\
\dot{1} \\
\dot{1}\end{array}$ & $\begin{array}{l}0 \\
\dot{0} \\
\dot{0} \\
\text { ur }\end{array}$ \\
\hline $\begin{array}{c}\text { SFVW-Set } \\
37\end{array}$ & $\begin{array}{l}+ \\
\text { 응 }\end{array}$ & 10 & $\checkmark$ & $\checkmark$ & $\checkmark$ & $5:$ & $\checkmark$ & $\checkmark$ & $\checkmark$ & $\checkmark$ & $\checkmark$ & $\checkmark$ & $\checkmark$ & $\checkmark$ & $\checkmark$ & $\checkmark$ \\
\hline $\begin{array}{c}\text { SFVW-Set } \\
38\end{array}$ & $\checkmark$ & 10 & 20 & $\checkmark$ & $\checkmark$ & \begin{tabular}{|l|l}
0 \\
\\
\\
\end{tabular} & $\checkmark$ & $\checkmark$ & $\checkmark$ & $\checkmark$ & $\checkmark$ & $\checkmark$ & $\checkmark$ & $\checkmark$ & $\checkmark$ & $\checkmark$ \\
\hline $\begin{array}{c}\text { SFVW-Set } \\
39\end{array}$ & $\begin{array}{l}\text { 응 } \\
8\end{array}$ & 10 & 20 & $\checkmark$ & $\checkmark$ & $\begin{array}{l}0 \\
\\
\\
\end{array}$ & $\checkmark$ & $\checkmark$ & $\checkmark$ & $\checkmark$ & $\checkmark$ & $\checkmark$ & $\checkmark$ & $\checkmark$ & $\checkmark$ & $\checkmark$ \\
\hline $\begin{array}{c}\text { SFVW-Set } \\
40\end{array}$ & $\begin{array}{l}+ \\
8 \\
8\end{array}$ & 10 & $\checkmark$ & $\checkmark$ & $\checkmark$ & $\begin{array}{l}0 \\
\\
\\
\end{array}$ & $\checkmark$ & $\checkmark$ & $\checkmark$ & $\checkmark$ & $\checkmark$ & $\checkmark$ & $\checkmark$ & $\checkmark$ & $\checkmark$ & $\checkmark$ \\
\hline $\begin{array}{c}\text { SFVW-Set } \\
41\end{array}$ & $\checkmark$ & 10 & $\checkmark$ & $\checkmark$ & $\checkmark$ & $\begin{array}{l}0 \\
0 \\
\\
\end{array}$ & $\checkmark$ & $\checkmark$ & $\checkmark$ & $\checkmark$ & $\checkmark$ & $\checkmark$ & $\checkmark$ & $\checkmark$ & $\checkmark$ & $\checkmark$ \\
\hline $\begin{array}{c}\text { SFVW-Set } \\
42 \text { Two- } \\
\text { Layer }\end{array}$ & $\checkmark$ & $\checkmark$ & $\checkmark$ & $\checkmark$ & $\checkmark$ & $\checkmark$ & $\checkmark$ & $\checkmark$ & $\checkmark$ & $\checkmark$ & $\checkmark$ & $\checkmark$ & $\checkmark$ & $\checkmark$ & $\checkmark$ & $\checkmark$ \\
\hline $\begin{array}{c}\text { SFVW-Set } \\
43 \text { Two- } \\
\text { Layer }\end{array}$ & $\begin{array}{c}10 \\
0\end{array}$ & $\checkmark$ & $\checkmark$ & $\checkmark$ & $\checkmark$ & $\checkmark$ & $\checkmark$ & $\checkmark$ & $\checkmark$ & $\checkmark$ & $\checkmark$ & $\checkmark$ & $\checkmark$ & $\checkmark$ & $\checkmark$ & $\checkmark$ \\
\hline $\begin{array}{c}\text { SFVW-Set } \\
44 \text { Two- } \\
\text { Layer }\end{array}$ & $\checkmark$ & $\checkmark$ & 20 & $\checkmark$ & $\checkmark$ & $\checkmark$ & $\checkmark$ & $\checkmark$ & $\checkmark$ & $\checkmark$ & $\checkmark$ & $\checkmark$ & $\checkmark$ & $\checkmark$ & $\checkmark$ & $\checkmark$ \\
\hline $\begin{array}{c}\text { SFVW-Set } \\
45 \text { Two- } \\
\text { Layer }\end{array}$ & $\checkmark$ & $\checkmark$ & 20 & $\checkmark$ & $\checkmark$ & $\frac{0}{i}$ & $\checkmark$ & $\checkmark$ & $\checkmark$ & $\checkmark$ & $\checkmark$ & $\checkmark$ & $\checkmark$ & $\checkmark$ & $\checkmark$ & $\checkmark$ \\
\hline $\begin{array}{c}\text { SFVW-Set } \\
47 \\
\text { with/without } \\
\text { Hysteresis } \\
\end{array}$ & $\checkmark$ & $\checkmark$ & $\checkmark$ & $\checkmark$ & $\checkmark$ & $\checkmark$ & $\checkmark$ & $\checkmark$ & $\checkmark$ & $\checkmark$ & $\checkmark$ & $\checkmark$ & $\checkmark$ & $\checkmark$ & $\checkmark$ & $\checkmark$ \\
\hline $\begin{array}{c}\text { SFVW-Set } \\
48 \\
\text { with/without } \\
\text { Hysteresis }\end{array}$ & $\begin{array}{c}10 \\
0\end{array}$ & $\checkmark$ & $\checkmark$ & $\checkmark$ & $\checkmark$ & $\begin{array}{l}0 \\
\dot{1} \\
\dot{1} \\
0\end{array}$ & $\checkmark$ & $\checkmark$ & $\checkmark$ & $\checkmark$ & $\checkmark$ & $\checkmark$ & $\checkmark$ & $\checkmark$ & $\checkmark$ & $\checkmark$ \\
\hline
\end{tabular}


Table 4c SFVW-Sets analysed

\begin{tabular}{|c|c|c|c|c|c|c|c|c|c|c|c|c|c|c|c|c|}
\hline 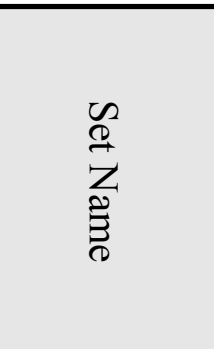 & $\begin{array}{l}\underset{\theta}{\theta} \\
\underset{\theta}{0}\end{array}$ & $\sum_{j}^{T}$ & 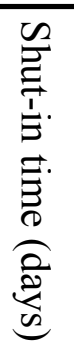 & 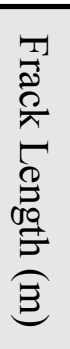 & $\begin{array}{l}\text { 忿 } \\
\text { అ }\end{array}$ & 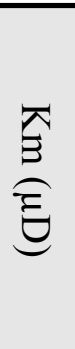 & $\overrightarrow{\tilde{E}}$ & 藏 & 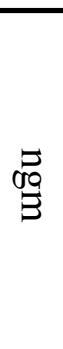 & $\underset{\Xi}{\Xi}$ & 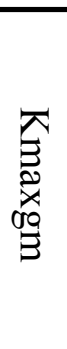 & 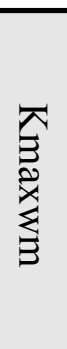 & $\stackrel{\overrightarrow{0}}{\stackrel{90}{\rightarrow}}$ & $\underset{\infty}{E}$ & 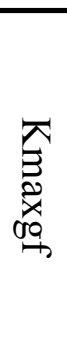 & 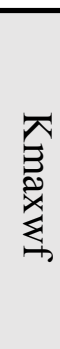 \\
\hline $\begin{array}{l}\text { Default } \\
\text { Values }\end{array}$ & 8 & $N$ & $N$ & $\frac{1}{8}$ & $\stackrel{\vec{\omega}}{0}$ & $\stackrel{+}{8}$ & $\vec{b}$ & $\stackrel{n}{u}$ & ir & $\stackrel{i}{1}$ & $\begin{array}{l}0 \\
\dot{i n} \\
1\end{array}$ & $\begin{array}{l}0 \\
\dot{0} \\
\text { ỳ } \\
\dot{a}\end{array}$ & 它 & $\dot{i}$ & in & $\begin{array}{l}0 \\
i \\
0 \\
\dot{0}\end{array}$ \\
\hline $\begin{array}{c}\text { SFVW-Set } \\
49\end{array}$ & $\begin{array}{c}10 \\
0\end{array}$ & 10 & $\checkmark$ & $\begin{array}{c}10 \\
0\end{array}$ & $\checkmark$ & $\checkmark$ & $\checkmark$ & $\checkmark$ & $\checkmark$ & $\checkmark$ & $\checkmark$ & $\checkmark$ & $\checkmark$ & $\checkmark$ & $\checkmark$ & $\checkmark$ \\
\hline $\begin{array}{c}\text { SFVW-Set } \\
50 \\
\end{array}$ & 웅 & 10 & $\checkmark$ & $\begin{array}{c}10 \\
0 \\
\end{array}$ & $\checkmark$ & $\checkmark$ & $\checkmark$ & $\checkmark$ & $\checkmark$ & $\checkmark$ & $\checkmark$ & $\checkmark$ & $\checkmark$ & $\checkmark$ & $\checkmark$ & $\checkmark$ \\
\hline $\begin{array}{c}\text { SFVW-Set } \\
51\end{array}$ & $<$ & 10 & $\checkmark$ & $\begin{array}{c}10 \\
0\end{array}$ & $\checkmark$ & $\begin{array}{l}0 \\
\dot{1} \\
\dot{1} \\
0\end{array}$ & $\checkmark$ & $\checkmark$ & $\checkmark$ & $\checkmark$ & $\checkmark$ & $\checkmark$ & $\checkmark$ & $\checkmark$ & $\checkmark$ & $\checkmark$ \\
\hline $\begin{array}{c}\text { SFVW-Set } \\
52\end{array}$ & $\checkmark$ & 10 & $\checkmark$ & $\begin{array}{c}10 \\
0\end{array}$ & $\checkmark$ & $\begin{array}{l}0 \\
0 \\
0 \\
1 \\
1\end{array}$ & $\checkmark$ & $\checkmark$ & $\checkmark$ & $\checkmark$ & $\checkmark$ & $\checkmark$ & $\checkmark$ & $\checkmark$ & $\checkmark$ & $\checkmark$ \\
\hline $\begin{array}{c}\text { SFVW-Set } \\
53\end{array}$ & $\begin{array}{l}\text { 옹 } \\
\text { 응 }\end{array}$ & 10 & $\checkmark$ & $\begin{array}{c}10 \\
0\end{array}$ & $\checkmark$ & $\begin{array}{l}0 \\
0 \\
0 \\
⺊ \\
⺊\end{array}$ & $\checkmark$ & $\checkmark$ & $\checkmark$ & $\checkmark$ & $\checkmark$ & $\checkmark$ & $\checkmark$ & $\checkmark$ & $\checkmark$ & $\checkmark$ \\
\hline $\begin{array}{c}\text { SFVW-Set } \\
54\end{array}$ & $<$ & 10 & 20 & $\begin{array}{c}10 \\
0\end{array}$ & $\checkmark$ & $<$ & $\checkmark$ & $\checkmark$ & $\checkmark$ & $\checkmark$ & $\checkmark$ & $\checkmark$ & $\checkmark$ & $\checkmark$ & $\checkmark$ & $\checkmark$ \\
\hline $\begin{array}{c}\text { SFVW-Set } \\
62, \\
\text { Swi }=50 \%\end{array}$ & $<$ & $\checkmark$ & $\checkmark$ & $\checkmark$ & $\checkmark$ & $<$ & $\checkmark$ & $\checkmark$ & $\checkmark$ & $\checkmark$ & $\checkmark$ & $\checkmark$ & $\checkmark$ & $\checkmark$ & $\checkmark$ & $\checkmark$ \\
\hline $\begin{array}{c}\text { SFVW-Set } \\
63, \\
\text { Swi }=75 \%\end{array}$ & $\checkmark$ & $\checkmark$ & $\checkmark$ & $\checkmark$ & $\checkmark$ & $\checkmark$ & $\checkmark$ & $\checkmark$ & $\checkmark$ & $\checkmark$ & $\checkmark$ & $\checkmark$ & $\checkmark$ & $\checkmark$ & $\checkmark$ & $\checkmark$ \\
\hline
\end{tabular}


Table 5 Parameters for the worst and the best scenarios for the Base Reference Set, Set 1.

\begin{tabular}{|c|c|c|c|c|}
\hline \multirow{2}{*}{ No. } & \multirow{2}{*}{\multicolumn{2}{|c|}{ Parameter }} & \multicolumn{2}{|l|}{ Case } \\
\hline & & & Worst & Best \\
\hline 1 & Fracture Permeability & $\mathrm{K}_{\mathrm{f}}(\mathrm{D})$ & 1 & 30 \\
\hline 2 & Matrix Permeability & $\mathrm{K}_{\mathrm{m}}(\mu \mathrm{D})$ & 1 & 100 \\
\hline 3 & \multirow[b]{2}{*}{ Matrix Capillary Pressure } & Pore Size Index, $\lambda$ & 4 & 1 \\
\hline 4 & & $\begin{array}{l}\text { Interfacial Tension, } \\
\text { IFT }(\mathrm{mNm} / \mathrm{m})\end{array}$ & 2 & 50 \\
\hline 5 & $\begin{array}{l}\text { The exponent of the Corey gas relative } \\
\text { permeability curve in the matrix }\end{array}$ & $\mathrm{n}_{\mathrm{gm}}$ & 5 & 1.5 \\
\hline 6 & $\begin{array}{l}\text { The exponent of the Corey fracture fluid } \\
\text { (water) relative permeability curve in the } \\
\text { matrix }\end{array}$ & $\mathrm{n}_{\mathrm{wm}}$ & 4 & 1.2 \\
\hline 7 & $\begin{array}{l}\text { The endpoint of Corey gas relative } \\
\text { permeability curve in the matrix }\end{array}$ & $\mathrm{K}_{\operatorname{maxgm}}$ & 0.5 & 1.0 \\
\hline 8 & $\begin{array}{l}\text { Endpoint of Corey fracture fluid (water) } \\
\text { relative permeability curve in the matrix }\end{array}$ & $\mathrm{K}_{\operatorname{maxwm}}$ & 0.05 & 0.6 \\
\hline 9 & $\begin{array}{l}\text { The exponent of the Corey gas relative } \\
\text { permeability curve in fracture }\end{array}$ & $\mathrm{n}_{\mathrm{gf}}$ & 5 & 1.5 \\
\hline 10 & $\begin{array}{l}\text { The exponent of the Corey fracture fluid } \\
\text { (water) relative permeability curve in } \\
\text { fracture }\end{array}$ & $\mathrm{n}_{\mathrm{wf}}$ & 4 & 1.2 \\
\hline 11 & $\begin{array}{l}\text { The endpoint of Corey gas relative } \\
\text { permeability curve in fracture }\end{array}$ & $\mathrm{K}_{\operatorname{maxgf}}$ & 0.5 & 1.0 \\
\hline 12 & $\begin{array}{l}\text { The endpoint of Corey fracture fluid } \\
\text { (water) relative permeability curve in } \\
\text { fracture }\end{array}$ & $\mathrm{K}_{\text {maxwf }}$ & 0.1 & 0.75 \\
\hline 13 & Porosity & $\phi$ & 0.15 & \\
\hline 14 & Residual water saturation in fracture & $\mathrm{S}_{\mathrm{wrf}}$ & 0.15 & \\
\hline 15 & Residual water saturation in the matrix & $\mathrm{S}_{\mathrm{wrm}}$ & 0.15 & \\
\hline 16 & Residual gas saturation in fracture & $\mathrm{S}_{\mathrm{grf}}$ & 0.1 & \\
\hline 17 & Residual gas saturation in matrix & $\mathrm{S}_{\mathrm{grm}}$ & 0.1 & \\
\hline
\end{tabular}

\begin{tabular}{|c|c|c|c|c|c|c|c|}
\hline \multicolumn{8}{|c|}{ Table 6 RMSE and AAD\% for the fitted ILRSM for single/Two-Layer. } \\
\hline & & \multicolumn{2}{|c|}{10 days } & \multicolumn{2}{|c|}{30 days } & \multicolumn{2}{|c|}{370 days } \\
\hline & & RMSE & $\begin{array}{c}\begin{array}{c}\mathrm{AAD} \% \\
\text { for }\end{array} \\
\mathrm{GPL}>30 \%\end{array}$ & RMSE & $\begin{array}{c}\begin{array}{c}\mathrm{AAD} \% \\
\text { for } \\
\mathrm{GPL}>30 \%\end{array} \\
\end{array}$ & RMSE & $\begin{array}{c}\mathrm{AAD} \% \\
\text { for } \\
\mathrm{GPL}>30 \%\end{array}$ \\
\hline \multirow{2}{*}{$\begin{array}{c}\text { Set 1, Base } \\
\text { Reference } \\
\text { set }\end{array}$} & Two-Layer & 8.66 & $6.86 \%$ & 10.12 & $6.63 \%$ & 13.74 & $6.88 \%$ \\
\hline & Single Layer & 8.92 & $6.79 \%$ & 10.57 & $6.35 \%$ & 15 & $7.05 \%$ \\
\hline \multirow{2}{*}{ Set 3 , ST20 } & Two-Layer & 20.82 & $17.58 \%$ & 22.13 & $17.55 \%$ & 22.81 & $16.31 \%$ \\
\hline & Single Layer & 20.87 & $17.50 \%$ & 22.17 & $17.47 \%$ & 23.11 & $16.70 \%$ \\
\hline \multirow{2}{*}{$\begin{array}{c}\text { Set } 6 \text {, } \\
\text { Dp100 }\end{array}$} & Two-Layer & 12.83 & $9.38 \%$ & 14.64 & $10.87 \%$ & 19.34 & $0.76 \%$ \\
\hline & Single Layer & 13.77 & $9.76 \%$ & 15.81 & $10.55 \%$ & 21.17 & $4.34 \%$ \\
\hline \multirow{2}{*}{$\begin{array}{c}\text { Set 5, } \\
\text { Kmr10ST20 }\end{array}$} & Two-Layer & 8.98 & $10.6 \%$ & 9.5 & $12.27 \%$ & 16.1 & $29.8 \%$ \\
\hline & Single Layer & 18.7 & $24.08 \%$ & 19.2 & $26.12 \%$ & 22.8 & $51.8 \%$ \\
\hline
\end{tabular}




\section{Figures}

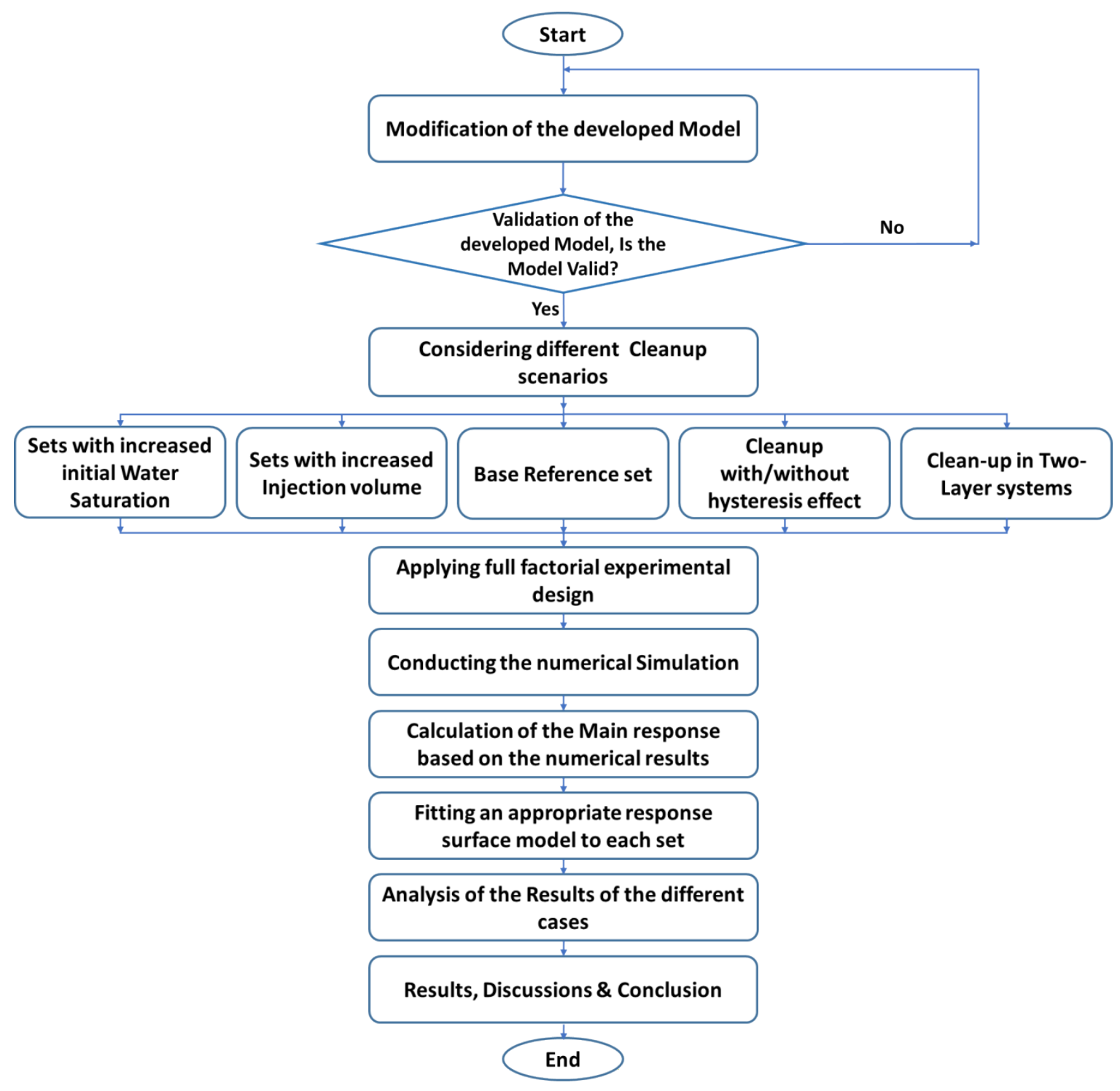

Figure 1 A flowchart explaining the method

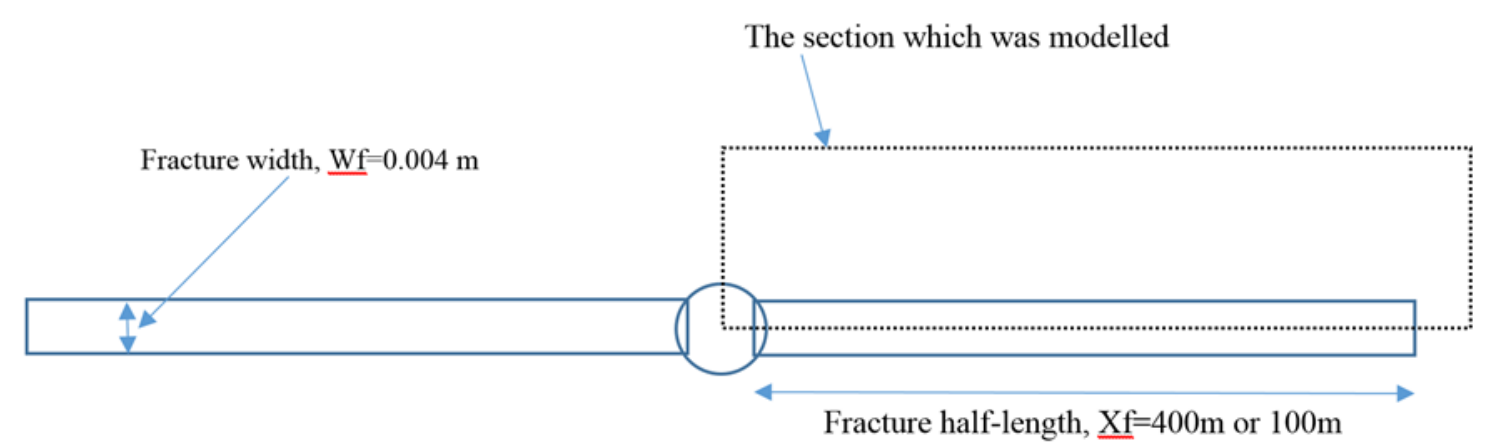

Figure 2 The section that is modelled 


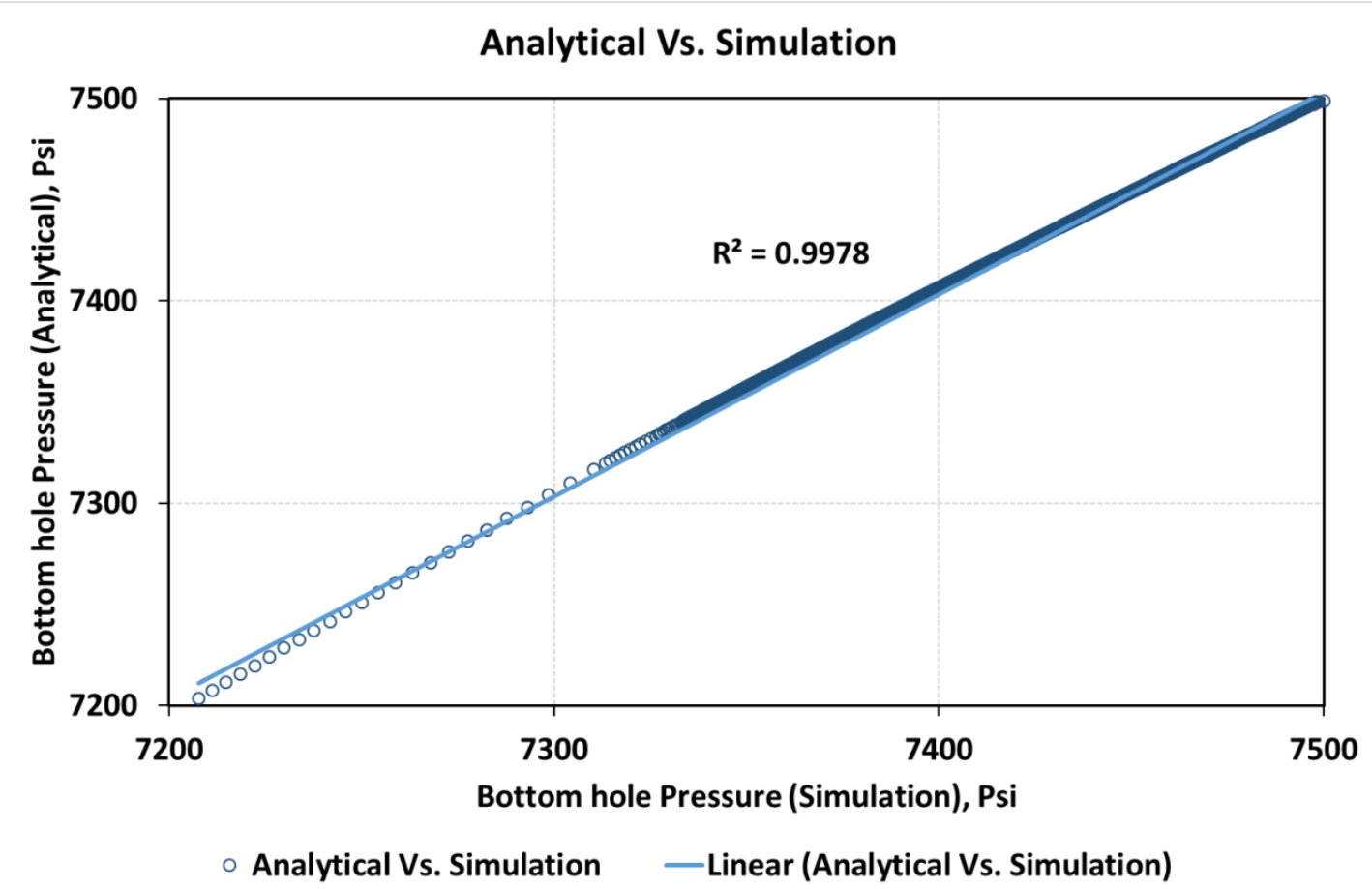

Figure 3 Predicated bottom hole pressure by the analytical model (Equation 2) vs the simulation model. 


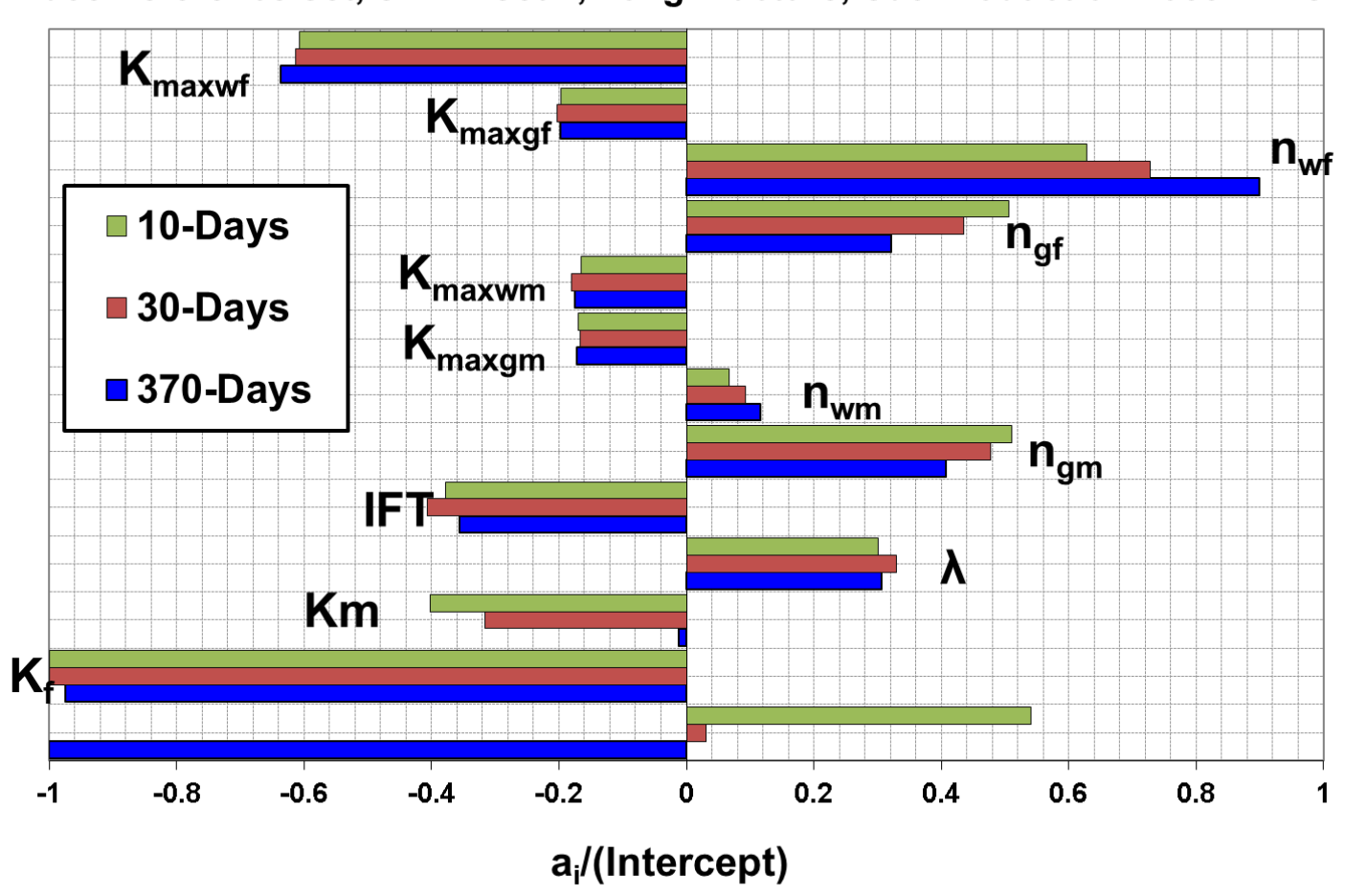

Figure 4 Tornado chart showing LRSM coefficients of all pertinent parameters in the Base Reference Set $(\mathrm{BC})$ at three production stages, $(\mathrm{FVR}=2, \mathrm{DP}=1000 \mathrm{psi}, \mathrm{ST}=2$ days and $\mathrm{Kmr}=1$ ).

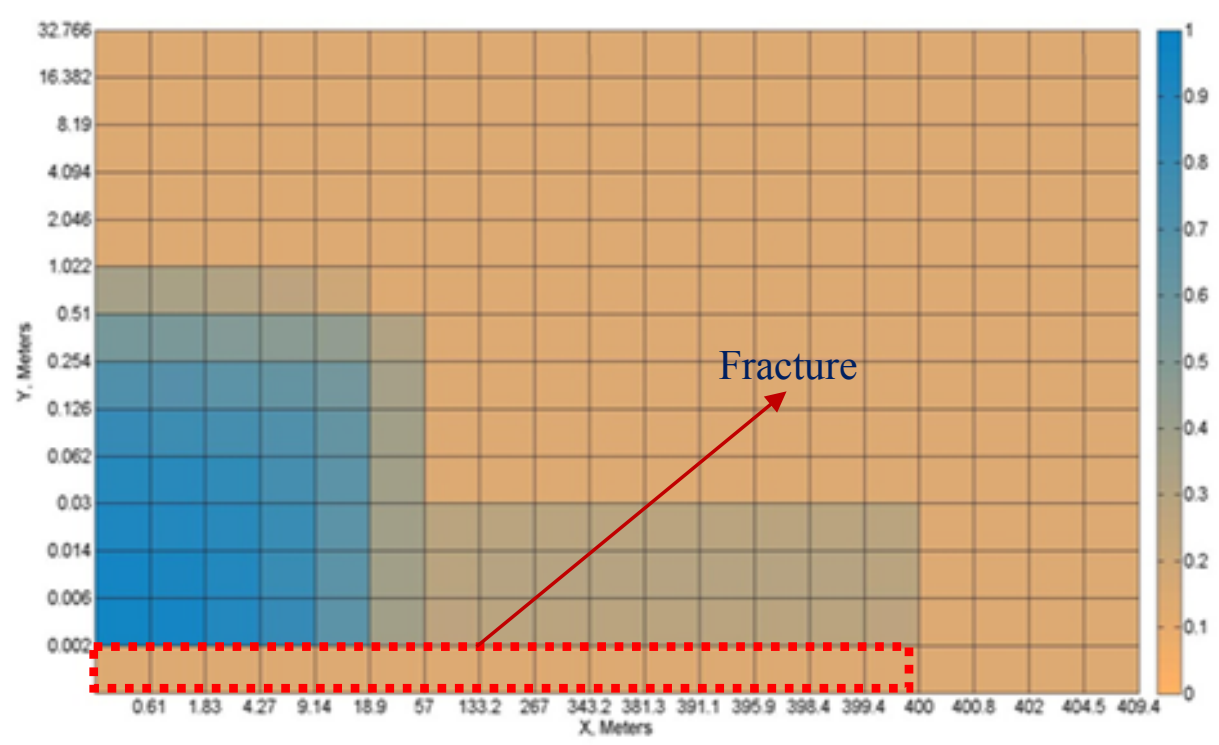

Figure 5 Fracturing Fluid saturation map of the best scenario of the Base Reference Set after 2 days of the shut-in period. 


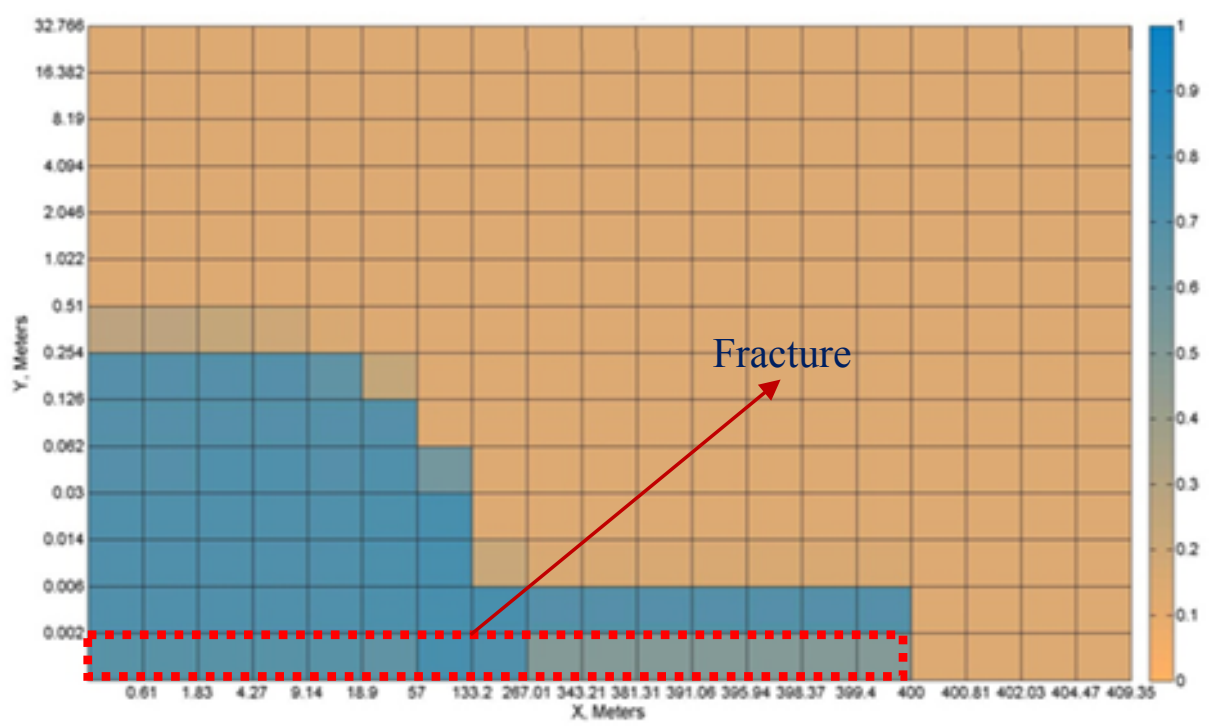

Figure 6 Fracturing Fluid saturation map of the worst scenario of the Base Reference Set after 2 days of the shut-in period.

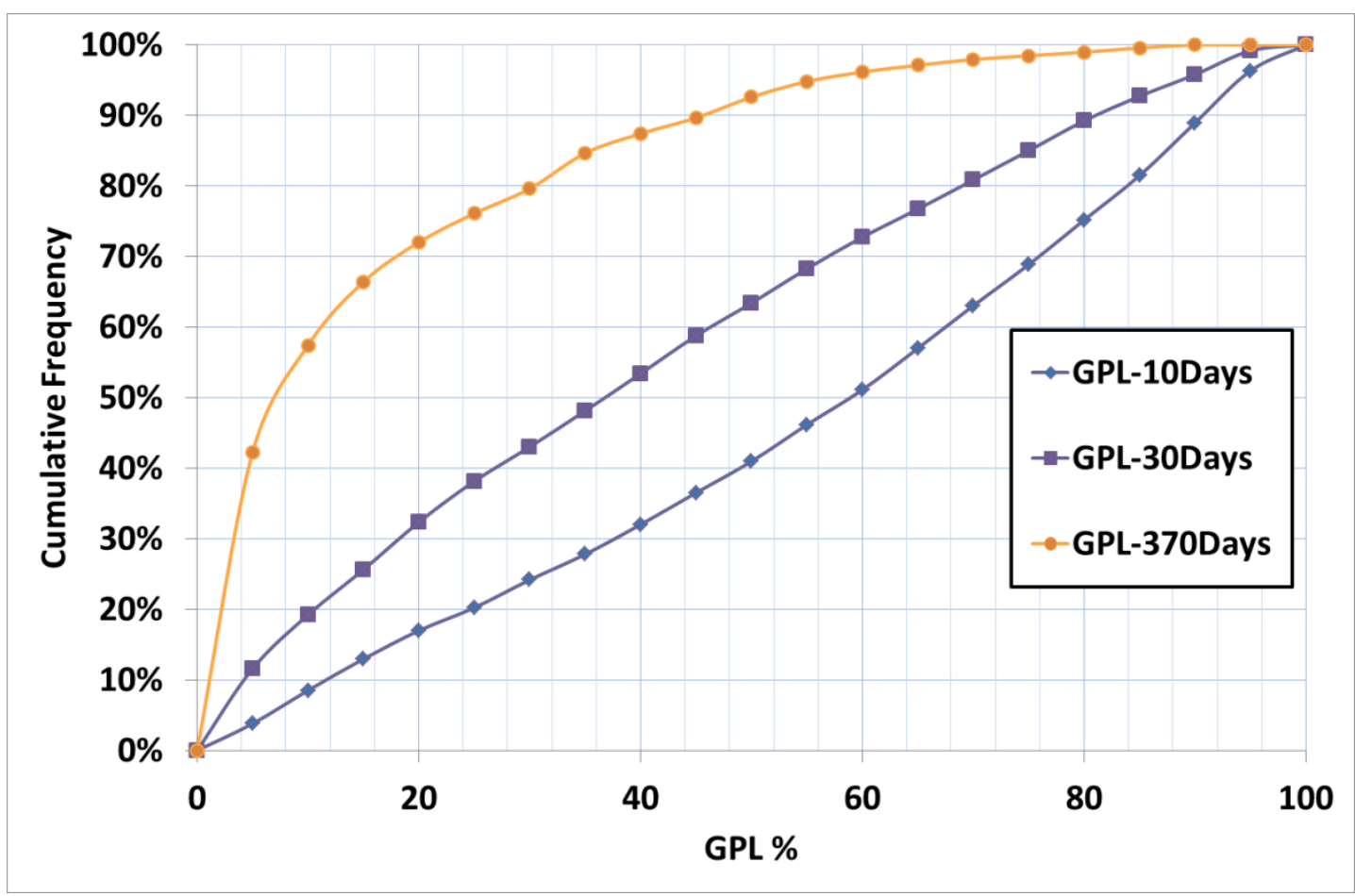

Figure 7 Histogram chart displaying cumulative frequency of the Base Reference Set (BC) at three production stages. 
Cumulative gas and water production for the best/worst case

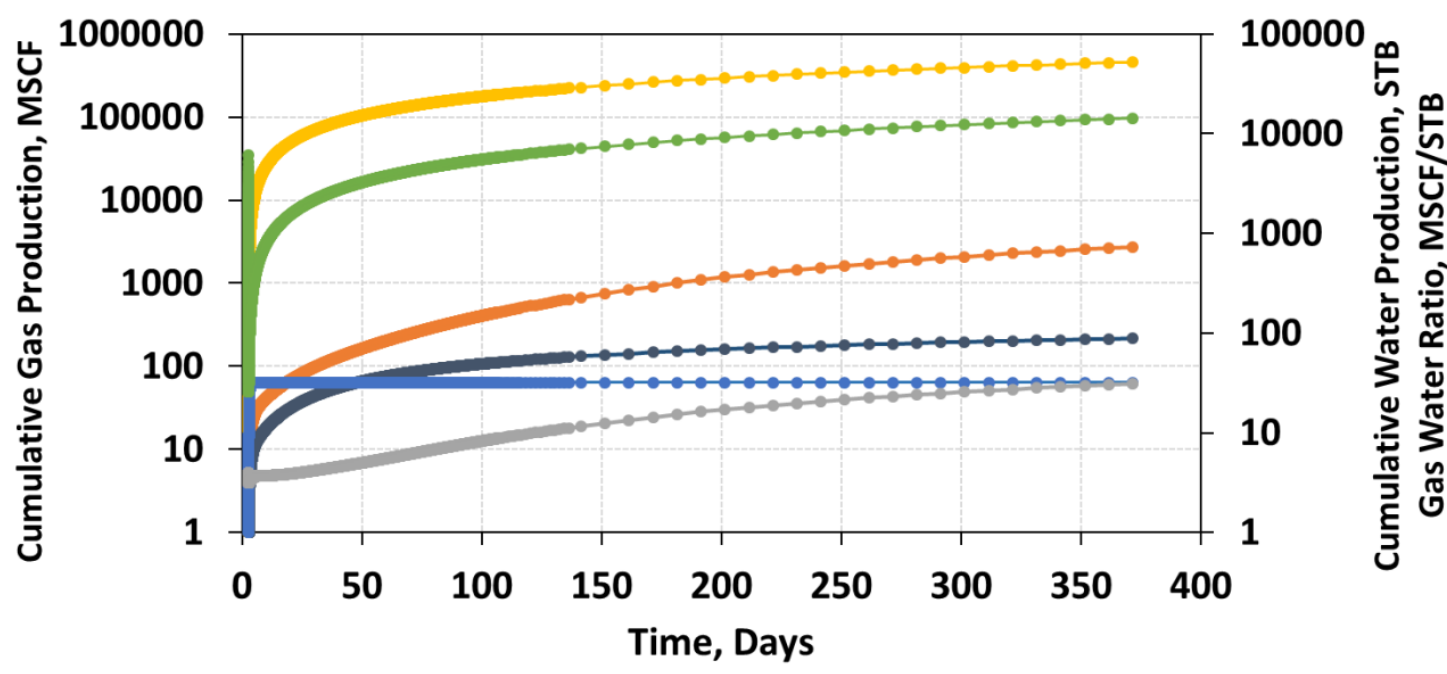

$\rightarrow$ Cumulative gas production, The worst case, MSCF

-- Cumulative gas production, The best case, MSCF

$\rightarrow$ Cumulative water production, The worst case, STB

$\rightarrow$ Cumulative water production, The best case, STB

$\multimap$ Cumulative GWR, The worst case, MSCF/STB

$\rightarrow-$ Cumulative GWR, The best case, MSCF/STB

Figure 8 Cumulative gas and water production for the best/worst case

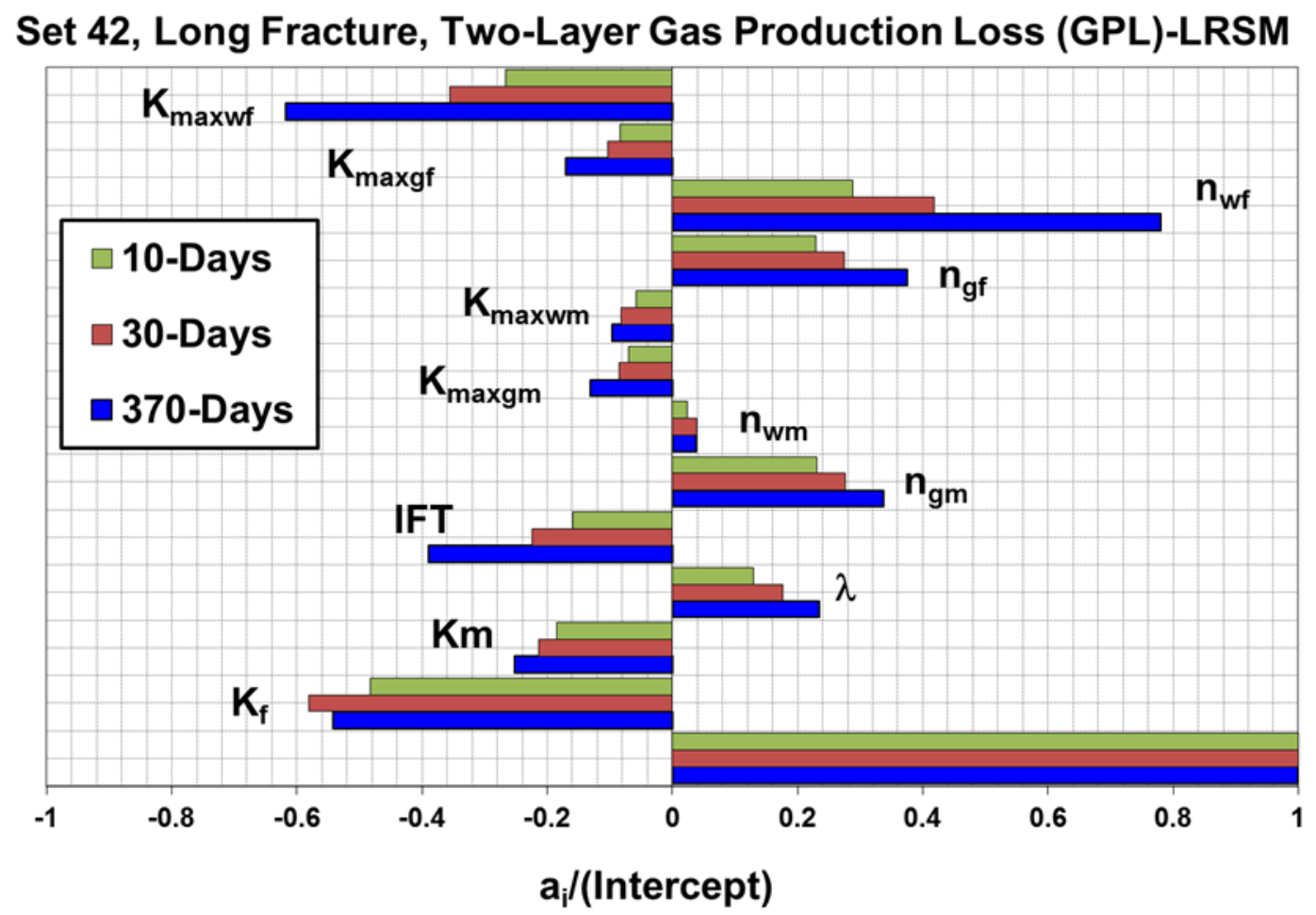

Figure 9 Tornado chart comparing LRSM coefficients of all pertinent parameters at three production stages for Two-Layer Base Reference Set, Long Fracture, Set 42. 
a. Layer 1, Top Layer, Set 42

Set 42, Long Fracture, Layer 1(Top) Gas Production Loss (GPL)-LRSM

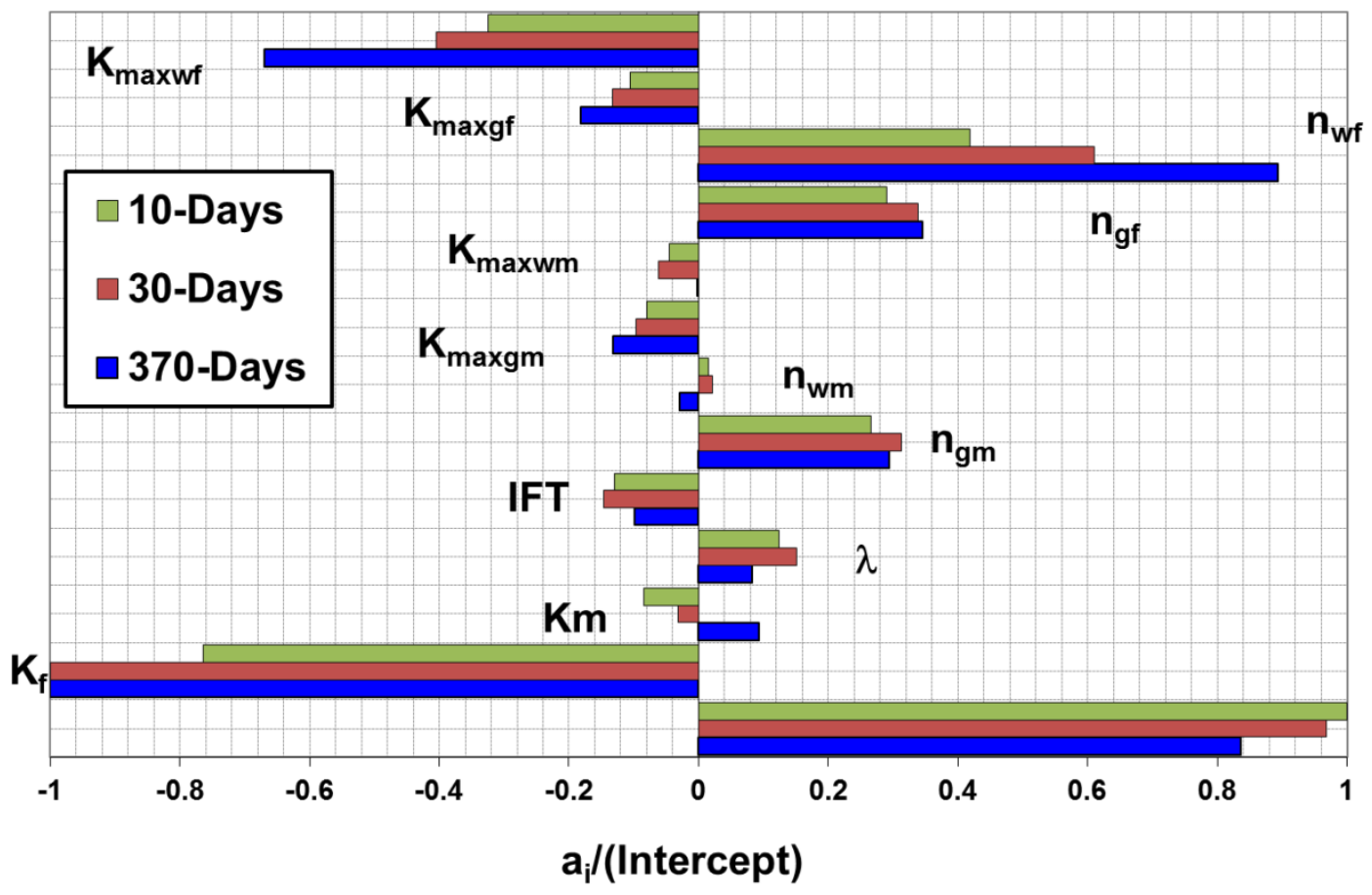

b. Layer 2, Bottom Layer, Set 42

Set 42, Long Fracture, Layer 2 (bottom) Gas Production Loss - LRSM

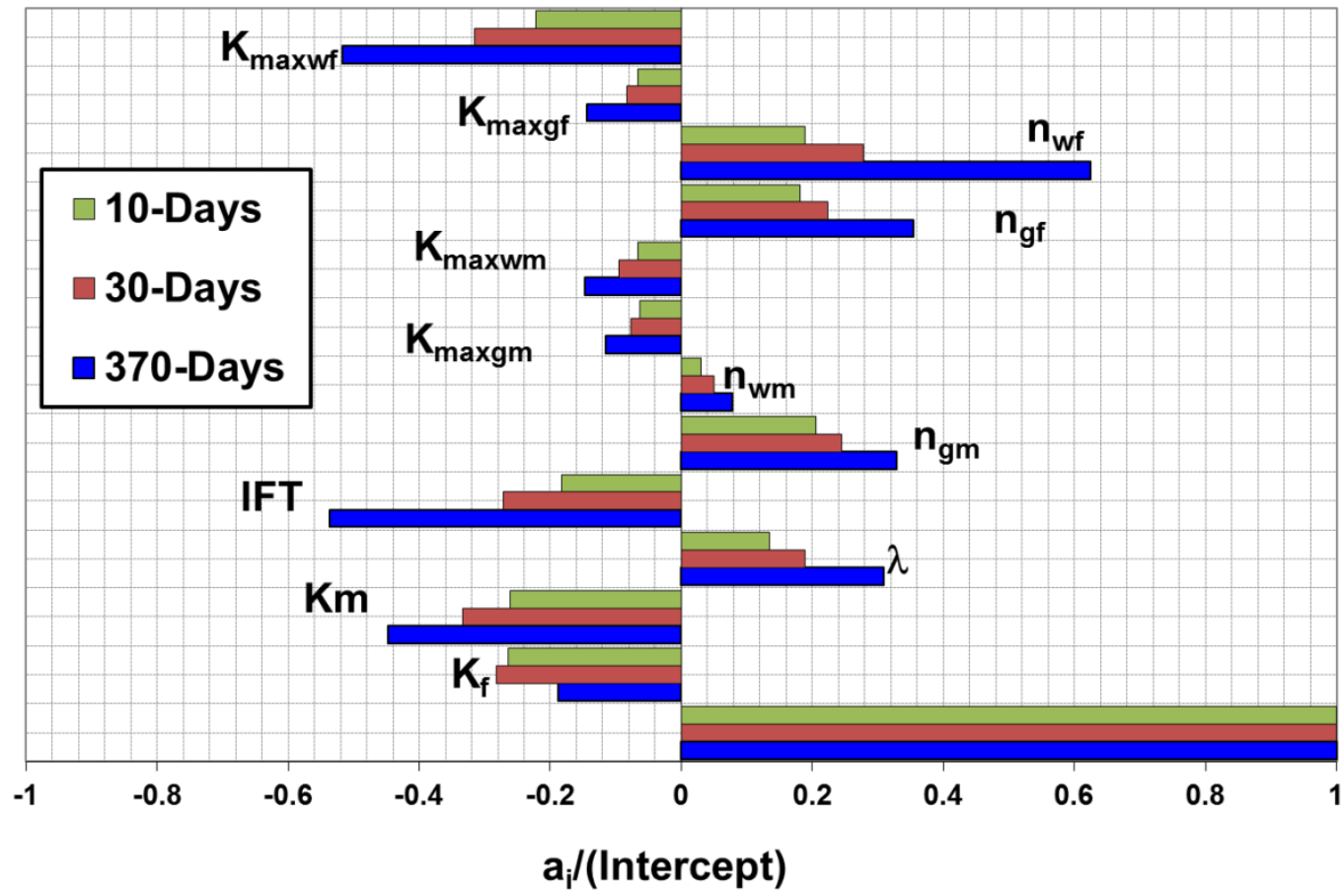

Figure 10 Tornado chart comparing LRSM coefficients of all pertinent parameters at three production stages for Two-Layer Base Reference Set, Long Fracture, Set 42(a) Layer 1, Top Layer and (b) Layer 2, Bottom Layer. 
Set 45, Long Fracture, Layer 2 (bottom) Gas Production Loss - LRSM

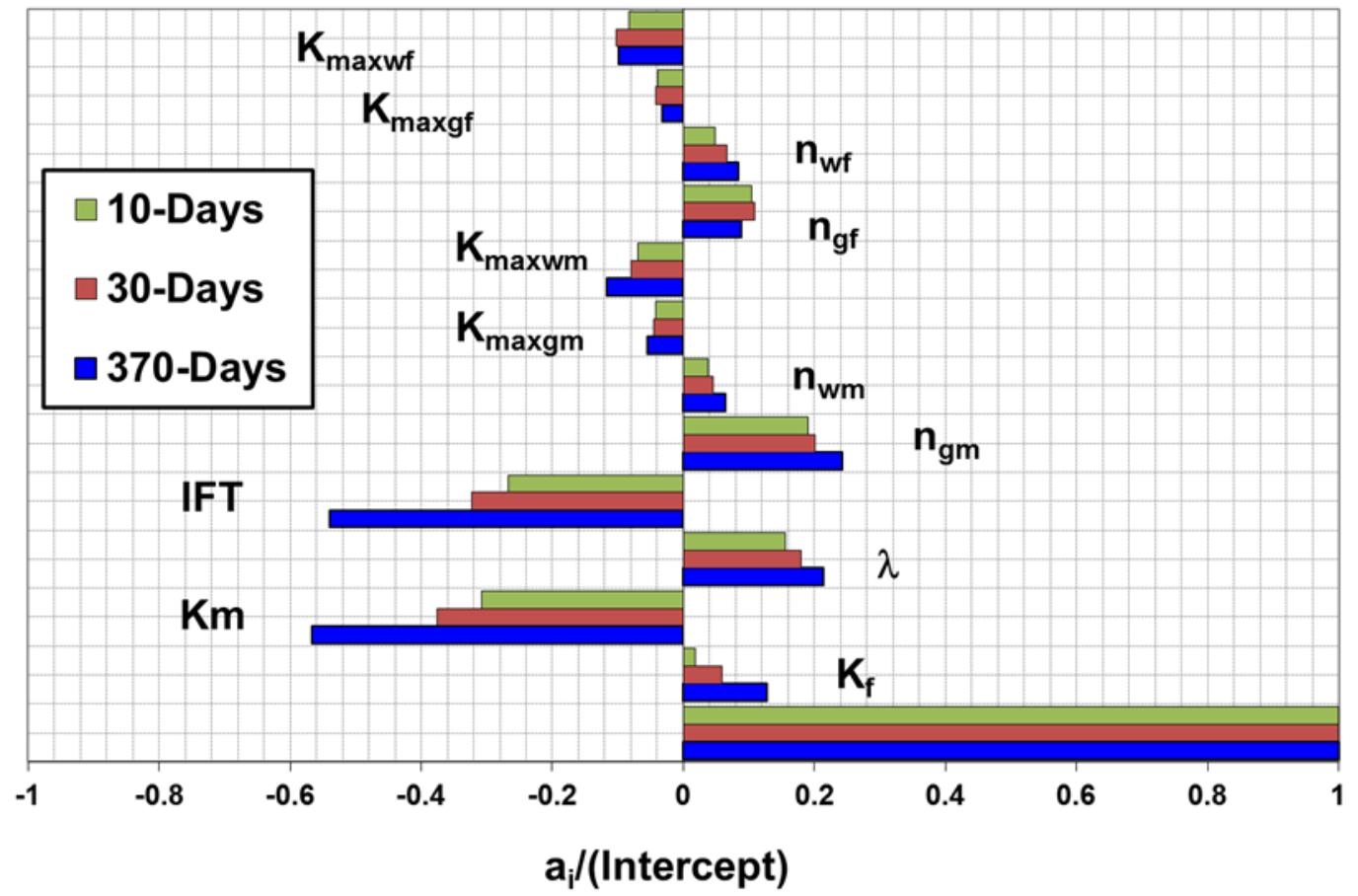

Figure 11 Tornado chart comparing LRSM coefficients of all pertinent parameters at three production stages for the Layer 2, Bottom Layer of set 45.

a. Base Reference set, with Hysteresis, Set 47

\section{Base Reference Set, Set 47, Long Fracture, with Hysteresis, GPL - LRSM}

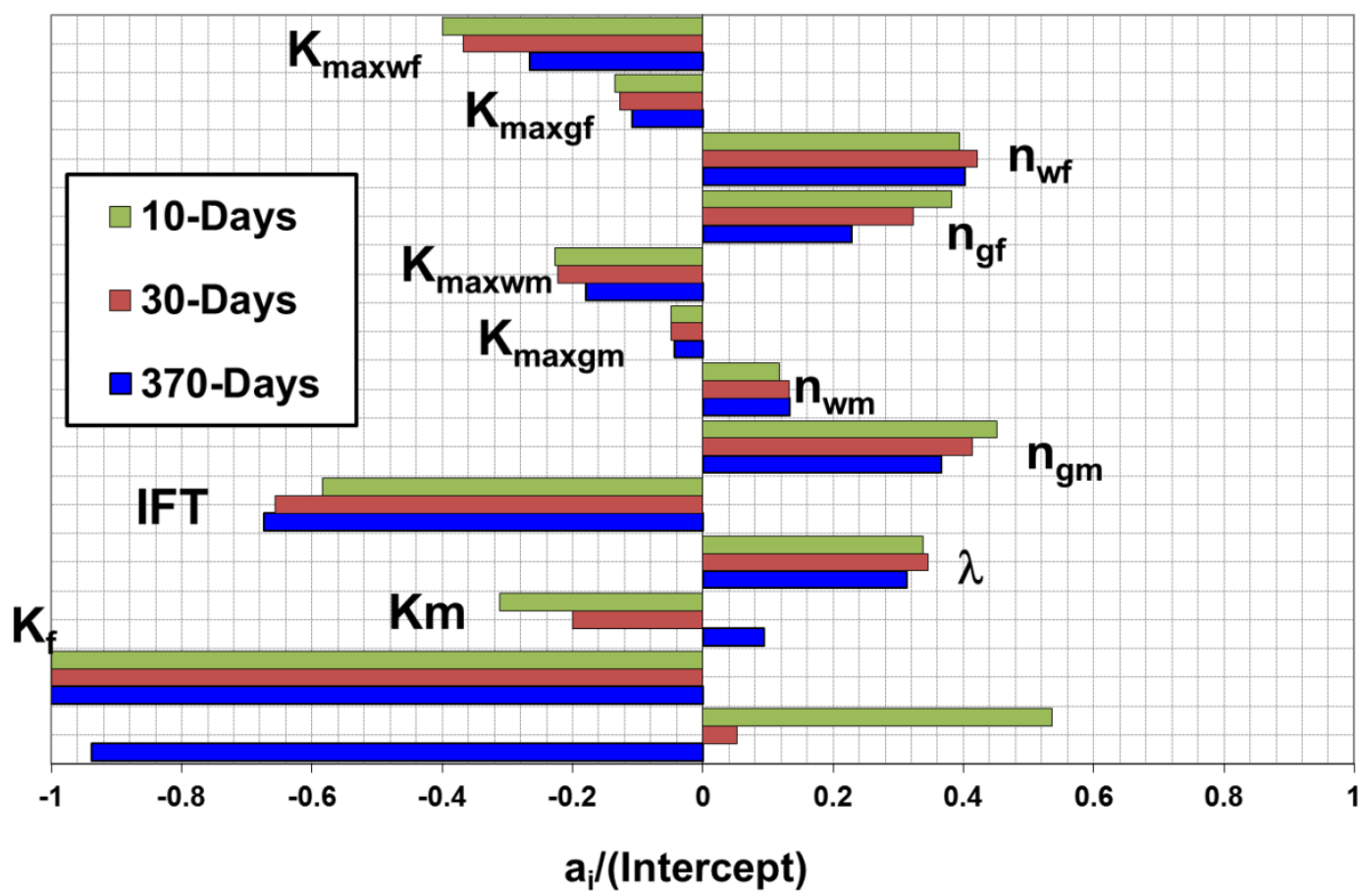

b. Base Reference set, without Hysteresis, Set 47 


\section{Base Reference Set, Set 47, Long Fracture, without Hysteresis, GPL - LRSM}

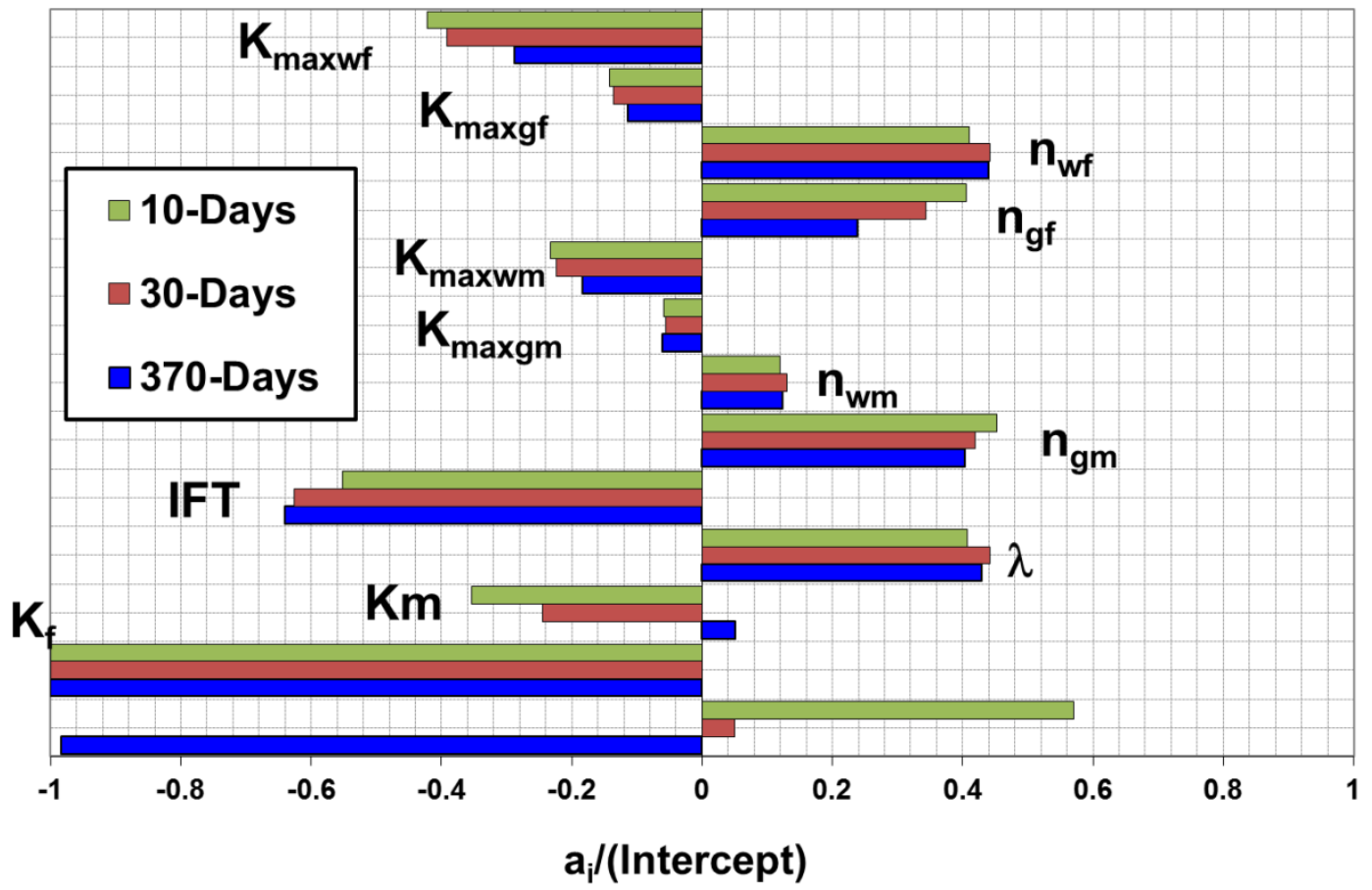

Figure 12: Tornado chart comparing LRSM coefficients of all pertinent parameters at three production stages for (a) Base Reference set, with Hysteresis, Set 47 (b) Base Reference set, with Hysteresis, Set 47

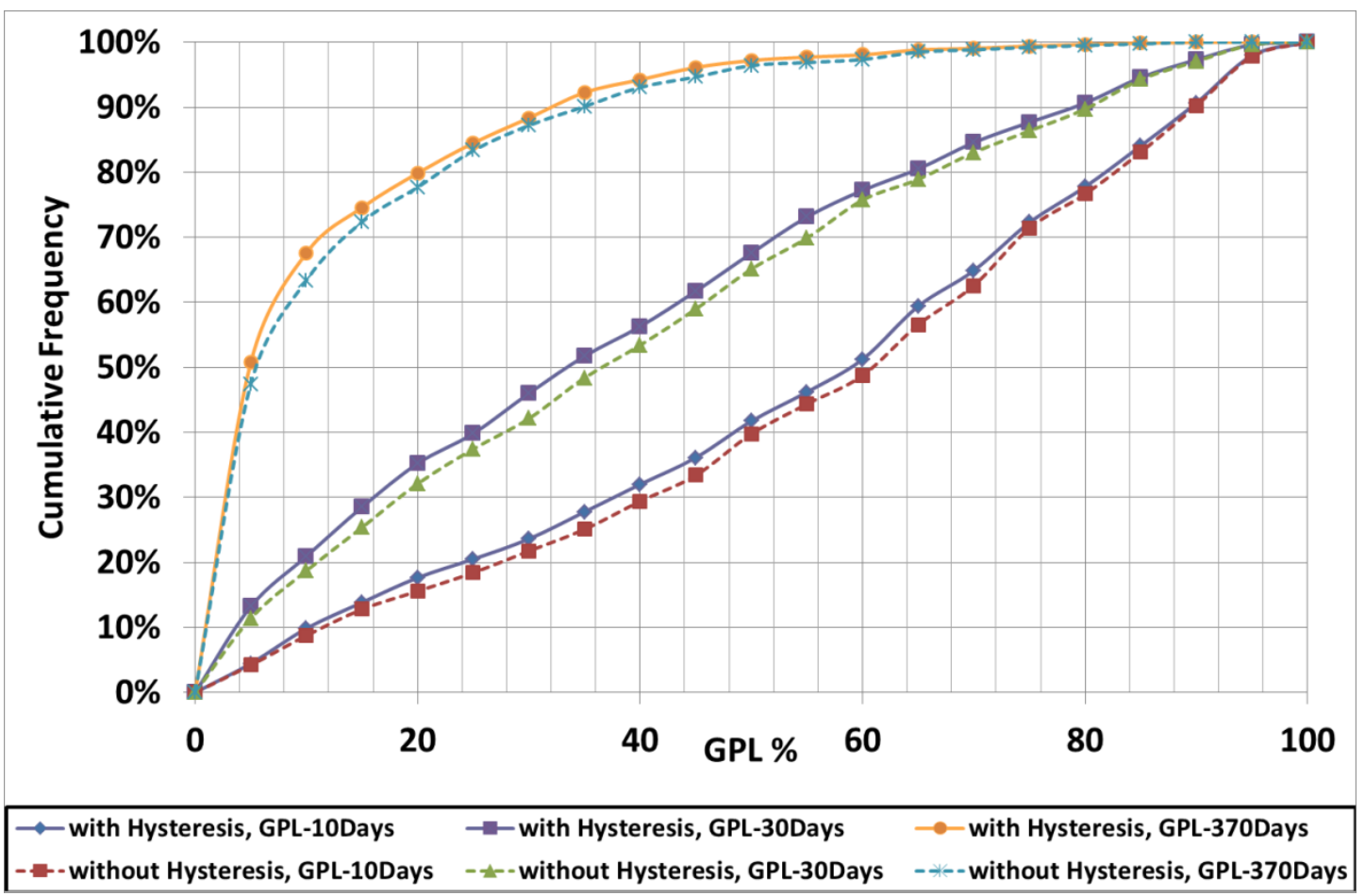

Figure 13: Histogram chart comparing GPL cumulative frequency of the Base Reference set with/without Hysteresis, Set 47 .at three production stages. 


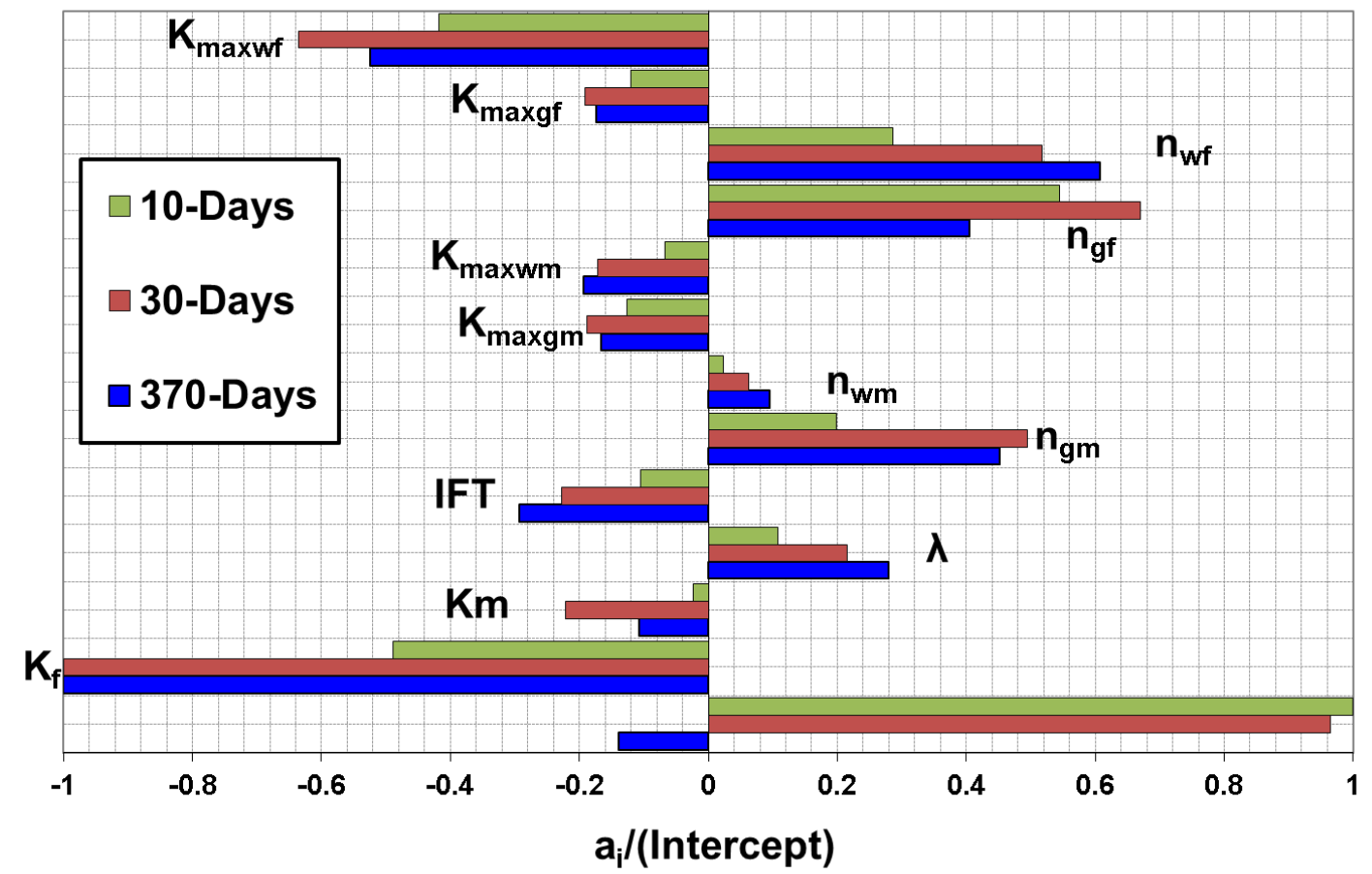

Figure 14 Tornado chart showing LRSM coefficients of all pertinent parameters in Set 2 with higher FVR at three production periods.

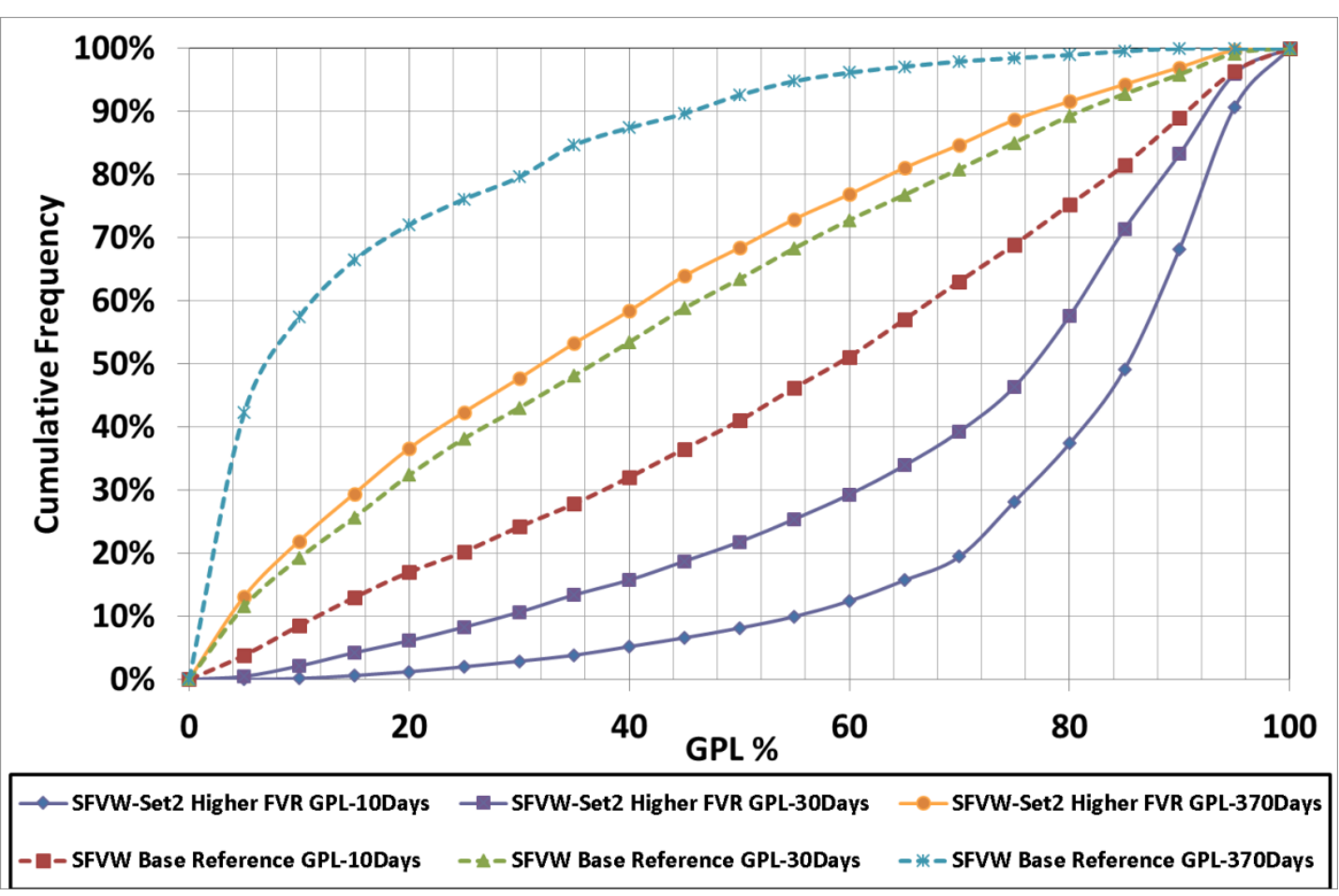

Figure 15 Histogram chart comparing the cumulative frequency of Set 2 with FVR=10 and Base Reference Set (BC) at three production periods. 
Figure 16 Fracturing Fluid saturation map of the best scenario of the Set2 (FVR=10) after 2 days of the shut-in period.

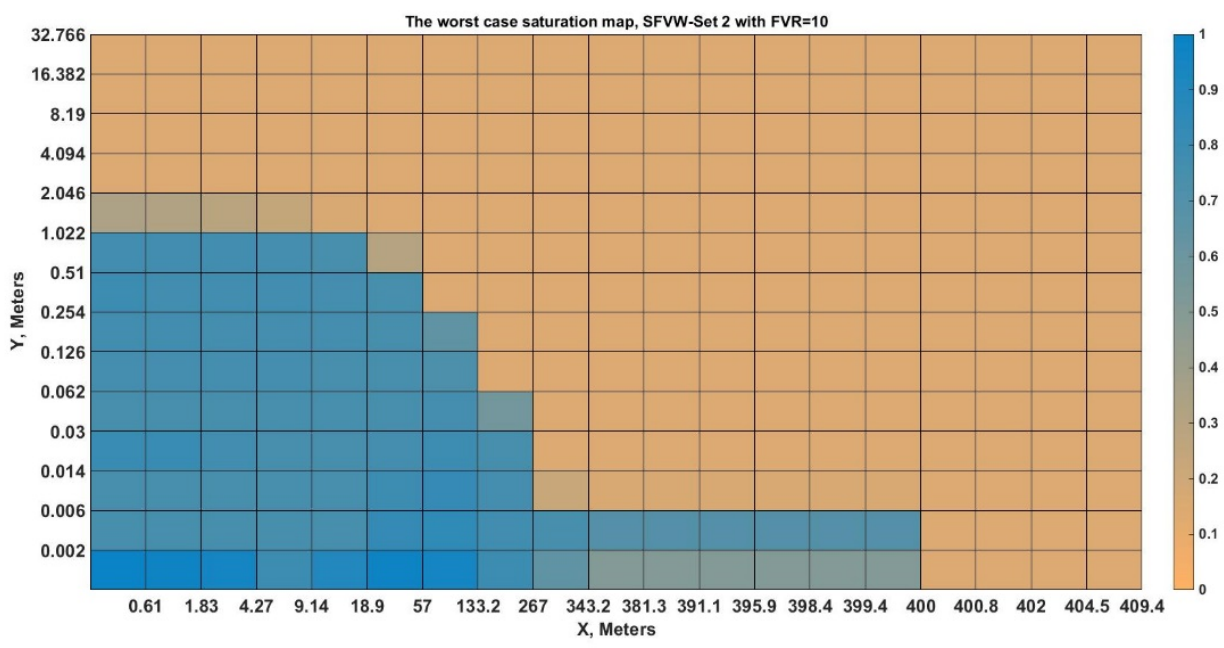

Figure 17 Fracturing Fluid saturation map of the worst scenario of the Set2 (FVR=10) after 2 days of the shut-in period. 
SFVW-Set 38, Gas Production Loss (GPL) - LRSM

Figure 18 Tornado chart comparing LRSM coefficients of all pertinent parameters at three production stages, in the Set with $\mathrm{FVR}=10, \mathrm{Kmr}=100, \mathrm{ST}=20$ days, Long Fracture.

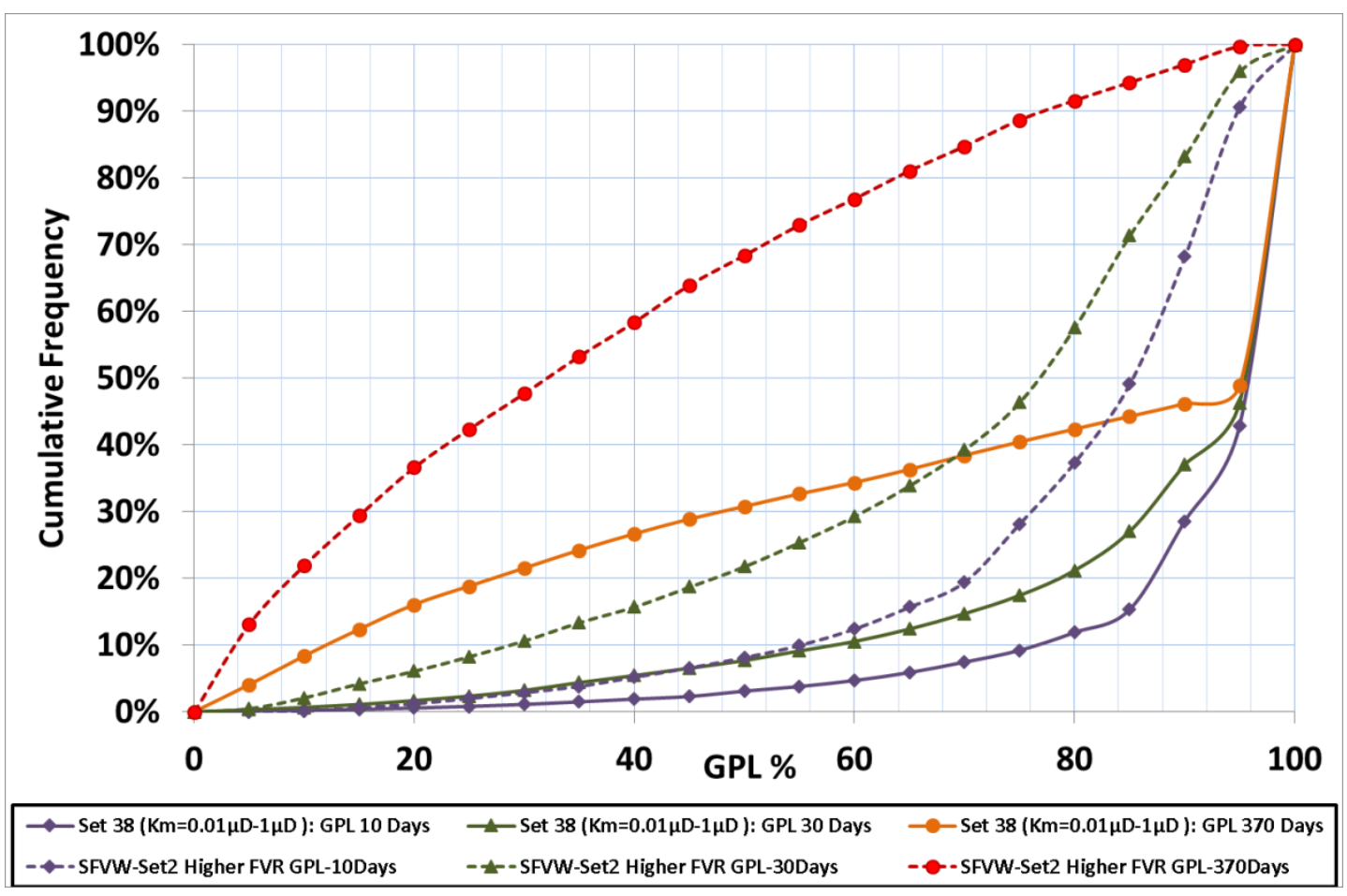

Figure 19 Histogram chart comparing the cumulative frequency of Set 38 with $F V R=10$, $\mathrm{Kmr}=100$ and $\mathrm{ST}=20$ and Set 2 with $\mathrm{FVR}=10$ at three production periods. 


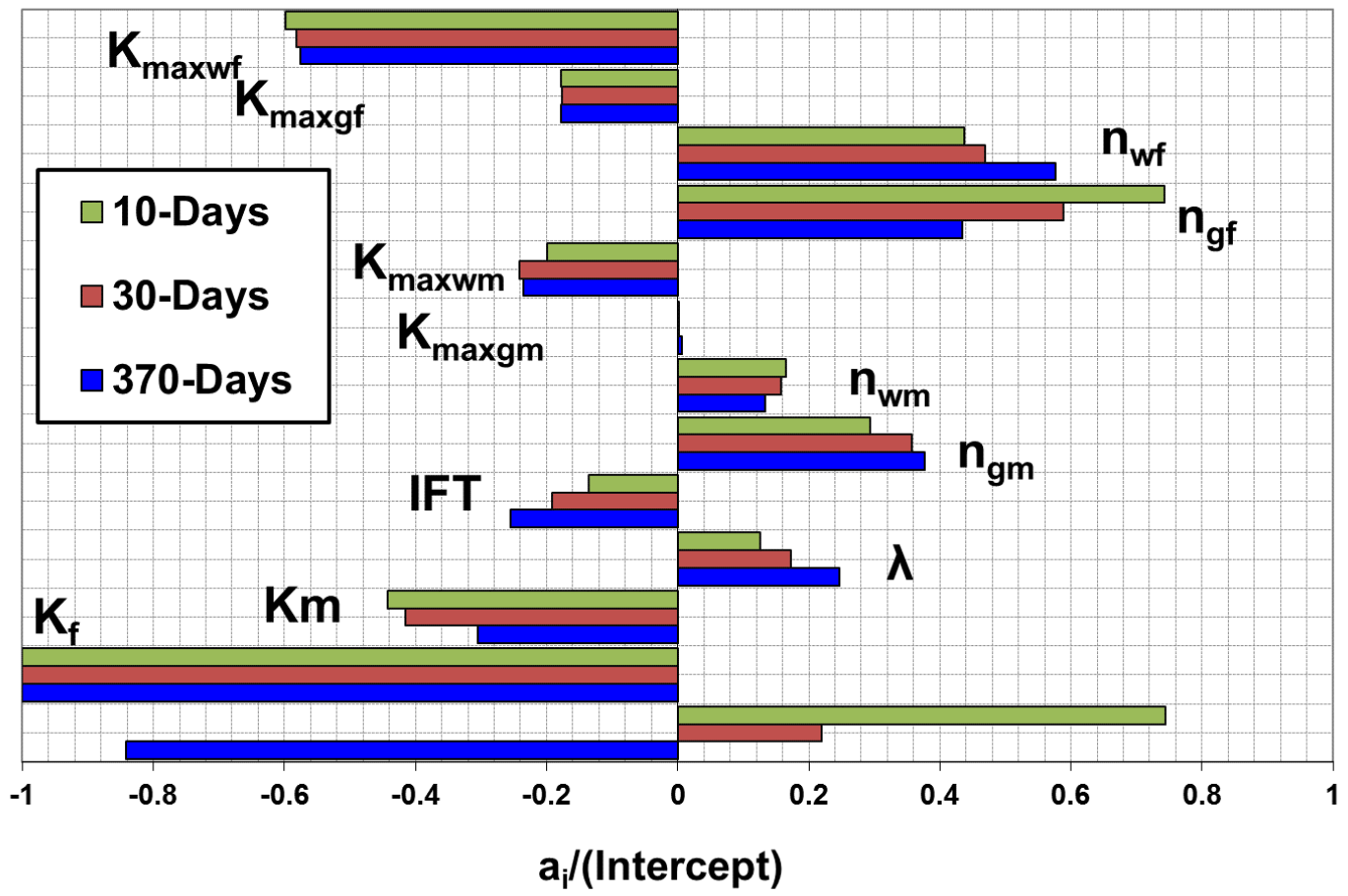

Figure 20 Tornado chart comparing LRSM coefficients of all pertinent parameters at three production stages, in Set $62(\mathrm{Swi}=50 \%$ \& Swirr=15\%), Long Fracture

SFVW-Set 63, Swi=75\% \& Swirr=15\%, Long Fracture, GPL - LRSM

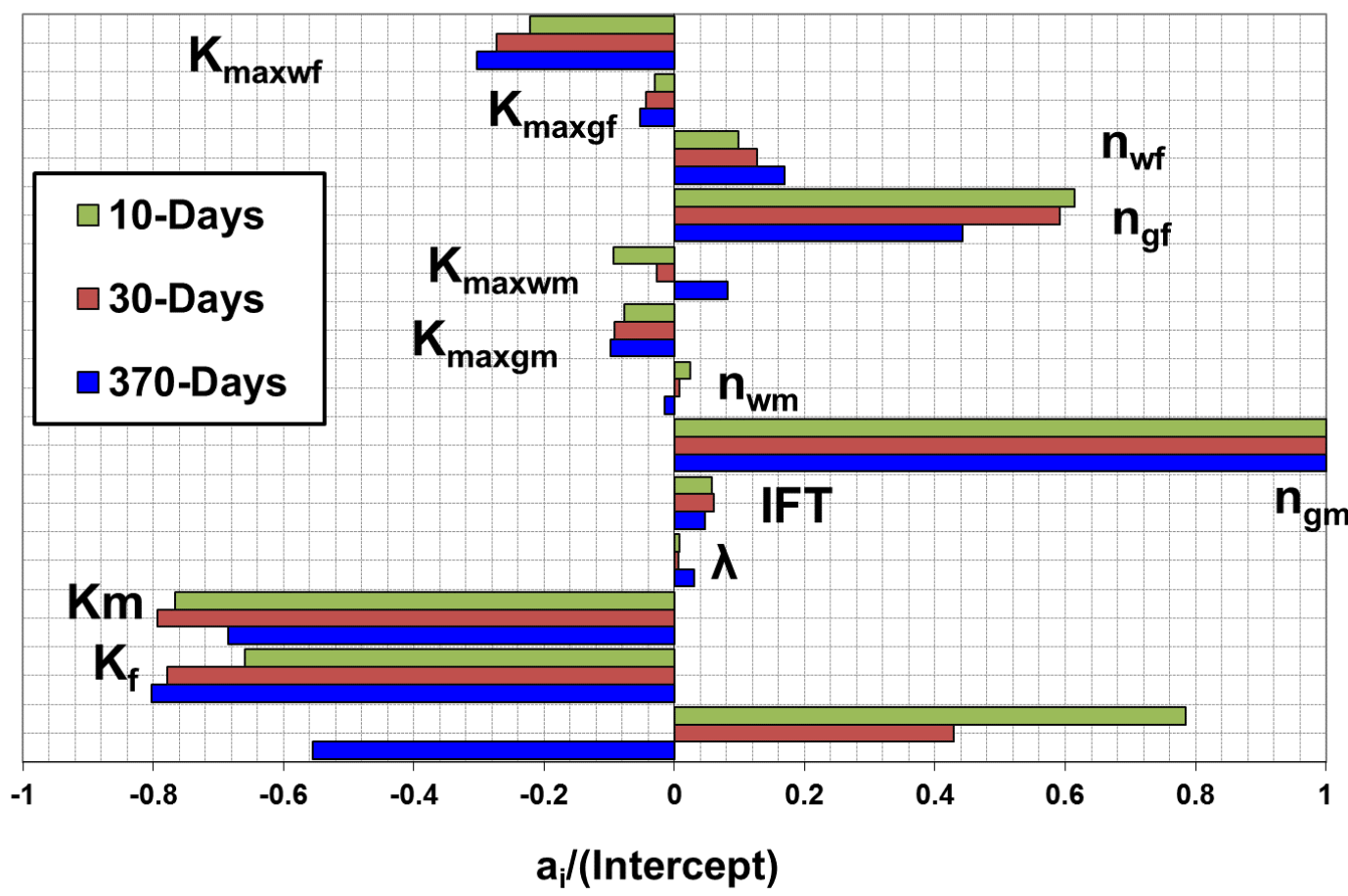

Figure 21 Tornado chart comparing LRSM coefficients of all pertinent parameters at three production stages, in Set $63(\mathrm{Swi}=75 \%$ \& Swirr $=15 \%)$, Long Fracture 


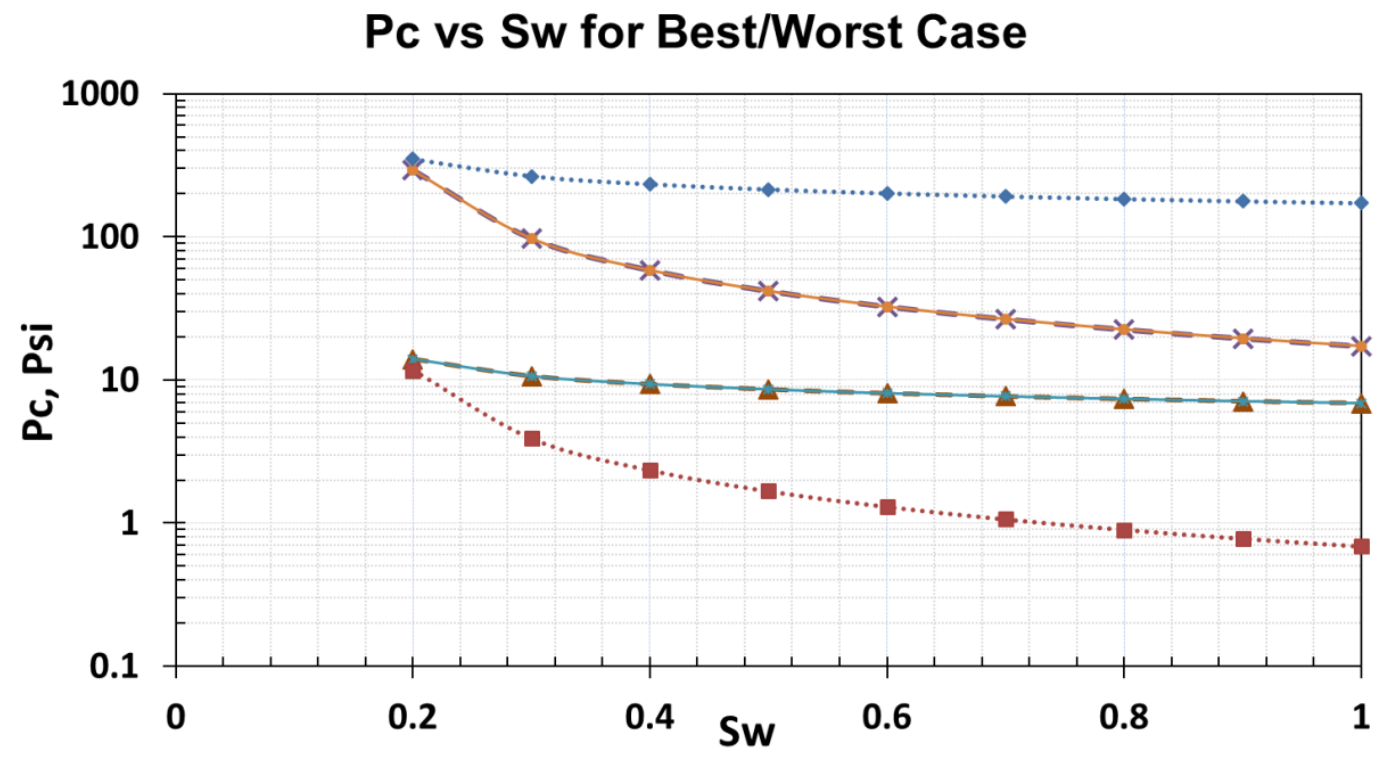

$-\Lambda$ SFVW-Set1, Base Rerference set, Worst Case

$-X$-SFVW-Set1, Base Rerference set, Best Case

\#-SFVW-Set62 Sw=50\%, Worst Case

$\rightarrow$ SFVW-Set62 Sw=50\%, Best Case

$\cdot$.. SFVW-Set63 Sw=75\%, Worst Case

..… SFVW-Set63 Sw=75\%, Best Case

Figure 22 Capillary pressure curves for Best/Worst case Base reference set, Set 1, Long Set $62(\mathrm{Sw}=50 \%)$ and Long $\mathrm{Set} 63(\mathrm{Sw}=75 \%)$.

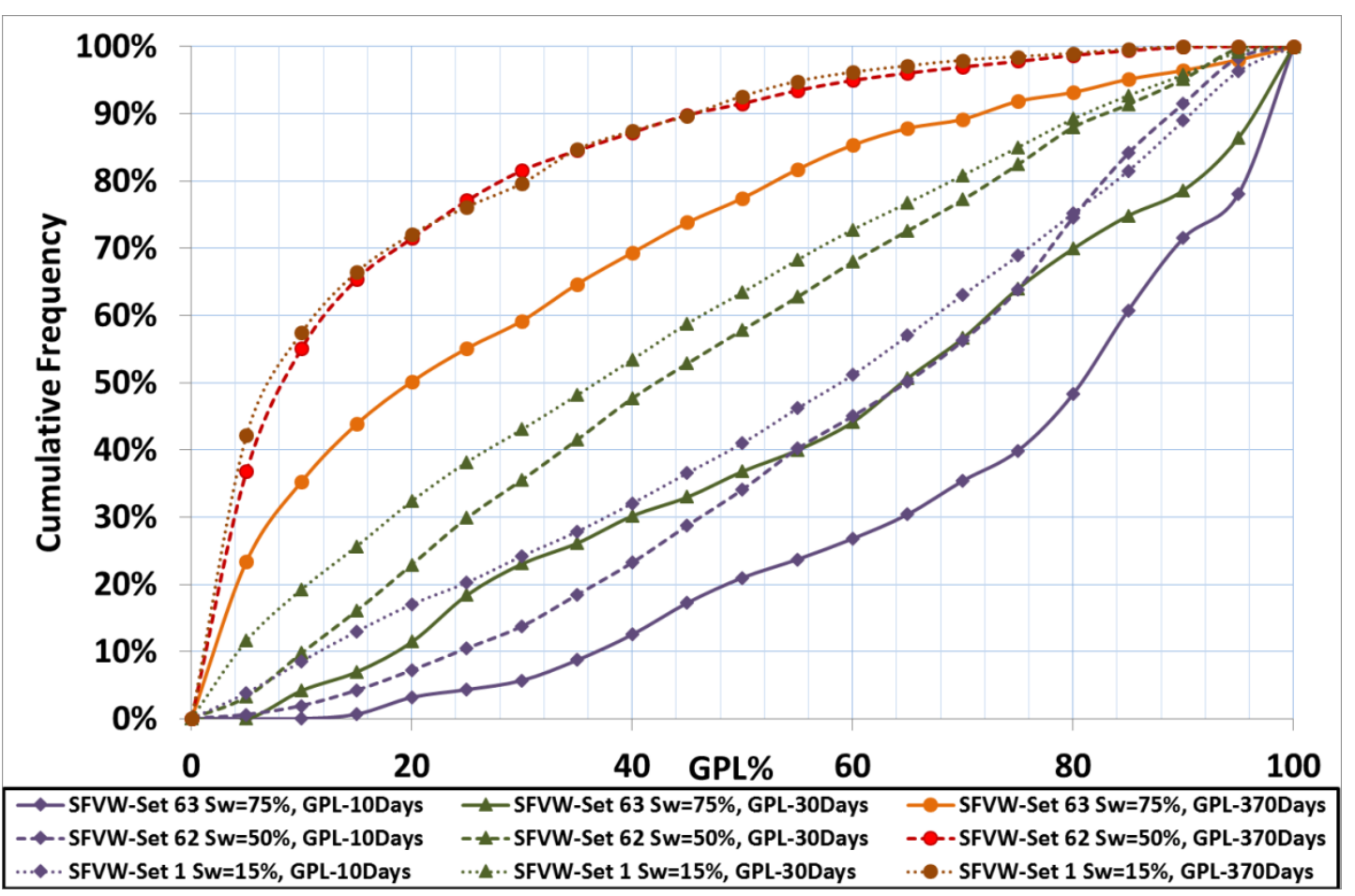

Figure 23 Histogram chart comparing GPL cumulative frequency of the Base reference set, Set 1 , Set $62(\mathrm{Sw}=50 \%)$ and Set $63(\mathrm{Sw}=75 \%)$. 